\title{
Regulatory mechanisms of immune checkpoints PD-L1 and CTLA-4 in cancer
}

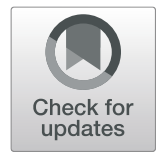

\author{
Hao Zhang ${ }^{1 \dagger}$, Ziyu Dai ${ }^{1 \dagger}$, Wantao Wu ${ }^{2}$, Zeyu Wang ${ }^{1}$, Nan Zhang ${ }^{3}$, Liyang Zhang ${ }^{1}$, Wen-Jing Zeng ${ }^{4}$, \\ Zhixiong Liu, ${ }^{1,5^{*}}$ and Quan Cheng ${ }^{1,5^{*}}$
}

\begin{abstract}
The cytotoxic T-lymphocyte-associated antigen 4 (CTLA-4)/B7 and programmed death 1 (PD-1)/ programmed cell death-ligand 1 (PD-L1) are two most representative immune checkpoint pathways, which negatively regulate T cell immune function during different phases of T-cell activation. Inhibitors targeting CTLA-4/B7 and PD1/PD-L1 pathways have revolutionized immunotherapies for numerous cancer types. Although the combined anti-CTLA-4/ B7 and anti-PD1/PD-L1 therapy has demonstrated promising clinical efficacy, only a small percentage of patients receiving anti-CTLA-4/B7 or anti-PD1/PD-L1 therapy experienced prolonged survival. Regulation of the expression of PD-L1 and CTLA-4 significantly impacts the treatment effect. Understanding the in-depth mechanisms and interplays of PD-L1 and CTLA-4 could help identify patients with better immunotherapy responses and promote their clinical care. In this review, regulation of PD-L1 and CTLA-4 is discussed at the levels of DNA, RNA, and proteins, as well as indirect regulation of biomarkers, localization within the cell, and drugs. Specifically, some potential drugs have been developed to regulate PD-L1 and CTLA-4 expressions with high efficiency.
\end{abstract}

Keywords: PD-L1, CTLA-4, Cancer immunotherapy, Regulatory mechanism, Drug intervention

\section{Background}

Immunotherapy, mediated by immune checkpoint inhibitor (ICI), represents a turning point in the antitumor treatment of various cancer types in recent years. So far, several immune checkpoint targets, like $\mathrm{T}$ cell immunoglobulin and mucin-domain containing-3 (TIM3), lymphocyte activation gene-3 (LAG-3), T cell immunoglobulin and ITIM domain (TIGIT), indoleamine 2, 3-dioxygenase 1 (IDO1), and V-domain immunoglobulin suppressor of $\mathrm{T}$ cell activation (VISTA), have been identified $[1,2]$, for which ICIs were designed and have presented promising results (Table S1). However, only ICIs targeting cytotoxic T lymphocyte antigen 4 (CTLA-4) and programmed cell death protein 1 (PD-1)/

\footnotetext{
* Correspondence: zhixiongliu@csu.edu.cn; chengquan@csu.edu.cn

${ }^{+}$Hao Zhang and Ziyu Dai contributed equally to this work.

'Department of Neurosurgery, Xiangya Hospital, Central South University, Changsha, China

Full list of author information is available at the end of the article
}

programmed cell death-ligand 1 (PD-L1) have been FDA-approved and widely used. CTLA-4 is a classical immune checkpoint molecule, acting as a CD28 homo$\log$ with a stronger binding affinity to its receptor B7-1 (CD80) or B7-2 (CD86). As the first available ICI, the humanized CTLA-4 antibody ipilimumab has revolutionized clinical cancer care and prolonged the 10-year survival for metastatic melanoma [3]. PD-1 is encoded by PDCD1, and its ligands, PD-L1 and PD-L2, are encoded by CD274 and CD273, respectively. Overall, PD-1/ PD-L1 axis has been more widely explored and applied than PD-1/ PD-L2 axis. CTLA-4/B7 and PD-1/ PD-L1 axis regulate physiological immune homeostasis, downregulate inflammatory responses, and presumptively facilitate immune evasion of cancer cells [4-6]. Blockade of PD-1/ PD-L1 axis and CTLA-4/B7 axis promoted overall survival in multiple cancer types with significantly increased response rates of therapy [3, 7]. Blockade of PD-1/ PD-L1 axis had decreased side effects 
compared with blockage of CTLA-4 [8, 9]. Notably, antibodies blocking the PD-1/PD-L1 axis have been approved as first-line or second-line treatment modalities in a wide range of cancers $[6,10]$. Further, combined anti-CTLA-4/B7 and anti-PD1/PD-L1 therapy has been applied to cancer treatment [11]. Nevertheless, despite promising clinical management results, only a minority of patients receiving ICIs targeting PD-L1 or CTLA-4 experience longer overall survival. Besides, ICIs failed to show significant therapeutic benefit in clinical trials of colorectal carcinoma (CRC) (confirmed responses in 7 of 84 patients), non-small cell lung cancer (NSCLC) (confirmed responses in 5 of 28 patients), melanoma (confirmed responses in 9 of 22 patients), and glioblastoma (confirmed response rate: 23.1\%) [12-14].

CTLA-4, primarily expressed by $\mathrm{T}$ cells, binds to CD80/CD86 and prevents the stimulatory signaling of $T$ cell proliferation provided by binding of CD28 with CD80/CD86 during the priming phase [15]. In contrast, the immune evasion process led by PD-1/ PD-L1 axis is primarily attributed to the overexpressed $\mathrm{PD}-\mathrm{L} 1$ on cancer cells which binds to PD-1 expressed on antigenstimulated $\mathrm{T}$ cells and inhibited the activity of PI3K/ AKT and Ras/MEK/ERK signaling pathways. Consequently, this impairs the proliferation, differentiation, and activation of $\mathrm{T}$ cells during the effector phase [16]. Besides tumor cells, PD-L1 could be expressed on tumor-infiltrating lymphocytes (TILs), including tumorassociated macrophages (TAMs), dendritic cells (DCs), regulatory $\mathrm{T}$ cells (Tregs), cancer-associated fibroblasts (CAFs), mast cells, and tumor stroma cells (astrocytes, vascular endothelial cells, keratinocytes) [4]. Therefore, PD-L1 overexpression on tumor cells, TILs, or tumor stroma cells inevitably triggers $\mathrm{T}$ cell exhaustion, thereby creating an immunosuppressive microenvironment and promotes tumor progression [17]. Correspondingly, PDL1 amplification has commonly been used as a positive predictive biomarker to blockade the PD-1/ PD-L1 axis in malignancies, including melanoma, NSCLC, and bladder cancer $[4,18,19]$. Multiple regulators influence PDL1 expression at DNA, RNA, protein level, and drug intervention via direct regulation. Further, the

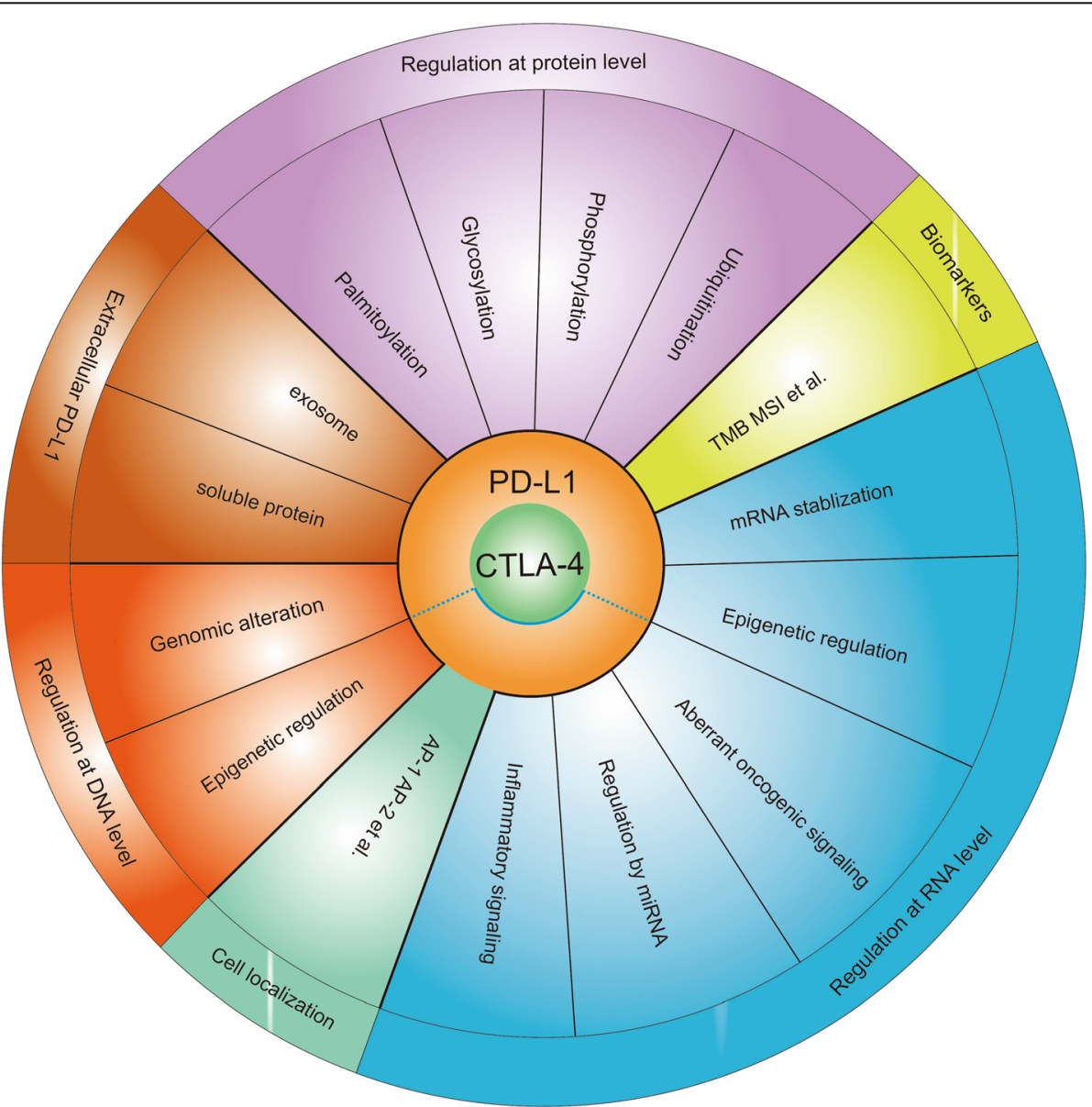

Fig. 1 Overall regulatory mechanisms of PD-L1 and CTLA-4. TMB, tumor mutation burden; MSI, microsatellite instability; AP-1, adaptor protein 1; AP-2, adaptor protein 2 . 
expression level of PD-L1 is predicted and indirectly regulated by different biomarkers. Similarly, CTLA-4 expression, specifically regulated by its localization within the cell, regulates anti-cancer responses [6]. Therefore, a comprehensive summary of PD-L1 and CTLA-4 regulators and their common regulatory mechanisms could help identify patients with favorable response to antiPD-L1 and anti-CTLA-4 treatments and promote their clinical management (Fig. 1).

\section{Searching strategy}

The gene regulation can be roughly categorized into three levels including transcription level, posttranscription level, and post-translation level. At different levels of gene regulation, there are different classical regulators. Therefore, we first designed a frame structure for PD-L1 and CTLA-4 regulation at three levels. Then, we carefully searched for the relevant references from PubMed illustrating PD-L1 regulation or CTLA-4 regulation from different perspectives using the following keywords such as inflammatory signaling (IL6, TGF-b, IFN-I), oncogenic signaling (EGFR, ERK, STAT), epigenic modifier, and protein modification (ubiquitination) et.al. We also tried to review the novel points of PD-L1 regulation or CTLA-4 regulation using the keywords such as exosome and cell localization. Finally, we systematically searched for the literatures illustrating drugs or compounds that target PD-L1 or CTLA-4 and influence the expression of these two genes.

\section{Regulation of PD-L1 and CTLA-4 at DNA level Genomic alterations at the CD274 locus}

CD274 is located on chromosome 9p24.1, where amplifications and translocations are linked to upregulated expression of PD-L1 in Hodgkin's lymphoma [20, 21], small cell lung cancer (SCLC) [22], NSCLC [23], lymphoma [24], Epstein-Barr virus (EBV)-positive gastric cancer [25], and oral squamous cell carcinoma (OSCC) [26]. Notably, in SCLC, CD274 amplification is caused by chromosome rearrangements without affecting the open reading frame [22] (Fig. 2, Table 1).

\section{Epigenetic regulations}

Histone acetylation and methylation regulate gene transcription epigenetically. Reports indicate that alternation of histone deacetylases (HDACs) expression promotes tumorigenesis [168]. In cancer cells with drug resistance, decreased COP1 enhanced JNK/C-Jun signaling activation, consequently inhibiting histone deacetylase 3 (HDAC3) expression. Subsequently, the enhanced histone $\mathrm{H} 3$ acetylation of the $\mathrm{CD} 274$ promoter upregulated PD-L1 expression [27]. As another HDAC family member, Histone deacetylase 6 (HDAC6) regulates histone acetylation by targeting nonhistone substrates. HDAC6 causes STAT3 phosphorylation, where HDAC6 and phospho-STAT3 are then recruited to the CD274 promoter, mediating the upregulation of PD-L1 in melanoma [28]. Additionally, HDAC inhibitors downregulate PD-L1 expression in melanoma [169], liver cancer [170], anaplastic thyroid cancer [171], NSCLC [172] and triplenegative breast cancer [173] which subsequently enhance and potentiate immunotherapy response. These findings collectively validate the use of HDAC inhibitors combined with PD-L1 inhibitors as a novel therapeutic option.

As the most common epigenetic changes in cancer, DNA hypomethylation at CpG sites enhances PD-L1 expression [174]. Accumulating evidence confirms that CD274 promoter methylation determines PD-L1 expression and predicts the survival of melanoma patients, NSCLC, head, and neck squamous cell carcinomas (HNSCC) CRC [29-32]. DNA methyltransferase inhibitors (DNMTis) were associated with elevated expression of PD-L1 in epithelial cancer cells [175, 176]. DNMTis was proposed to increase DNA hypermethylated endogenous retroviruses (ERVs) expression, which presumably stimulated IFN genes (STING) and generated IFN- $\gamma$ induced PD-L1 [174]. The upstream signaling protein of DNMTis, enhancer of zeste two polycomb repressive complex two subunits (EZH2), downregulated PD-L1 expression in hepatocellular carcinoma (HCC) [35]. TGF- $\beta 1$ inactivated DNMTs and demethylated CD274 promoter in NSCLC positively regulated PD-L1 expression [177], whereas TNF- $\alpha$ activated the nuclear factor kappa-lightchain-enhancer of activated B cells (NF-kB) pathway that demethylated CD274 promoter and promoted PD-L1 expression [177]. A recent study demonstrated that anti-PD1 therapy triggered more hypermethylated promoters of CD274 in the secondary gastric cardia adenocarcinoma (GCA) compared to the primary GCA without anti-PD-1 therapy [178]. Besides, DNA hypomethylating agent azacytidine combined with anti-PD-1 exhibited a better suppressing capability of tumor growth than anti-PD-1 therapy alone in the mice model [178].

H3K4me3 is an 'activating' histone modifier in reflecting gene transcription [179] and enriched with CD274 promoter in pancreatic cancer. The binding protein of the CD274 promoter, MLL1, catalyzes H3K4me3 to promote PD-L1 transcription [33]. The combined inhibition of MLL1 and anti-PD-1 immunotherapy significantly and synergistically suppresses pancreatic tumor growth [33]. Furthermore, H3K4me3 is actively implicated in epithelial to mesenchymal transition (EMT)-induced PD-L1 expression in breast cancer stem cells [34]. In contrast, H3K27me3, upregulated by EZH2, suppressed PD-L1 expression in HCC [35]. Additionally, epigenetic modulators targeting EZH2-mediated H3K27me3 enhances the efficacy of anti-PD-1 therapy [180]. 


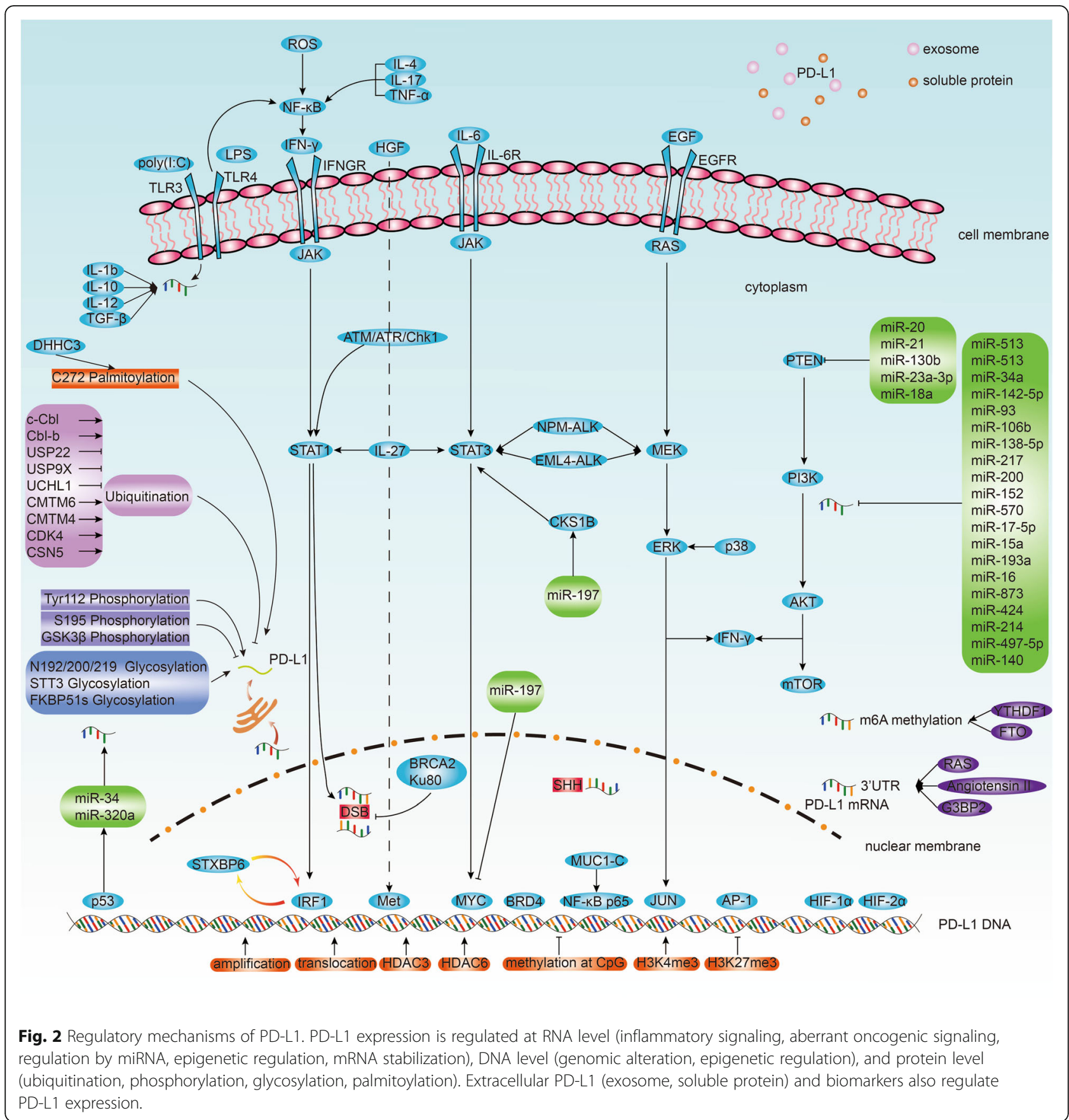

HDAC domain mutation in transcription factor Tcf1 promotes the CTLA-4 expression in T follicular helper (TFH) cells [181]. Also, methylation of DNA at CpG sites epigenetically suppressed CTLA-4 expression [182].

\section{Regulation of PD-L1 and CTLA-4 at RNA level Inflammatory signaling}

Evidence suggests that PD-1/ PD-L1 axis restrains T cell hyperactivity. Consistently, inflammatory signaling regulates the expression of PD-L1. Among the multiple soluble inflammatory factors, type II interferon, IFN- $\gamma$, primarily promotes PD-L1 production [183]. The blockage of IFN- $\gamma$ in the sarcoma mouse model tremendously abrogated PD-L1 expression [36]. In addition to diverse cancer types, IFN- $\gamma$-induced PD-L1 is extended in healthy tissues and immune cells [4]. As a proinflammatory cytokine, IFN- $\gamma$ is largely produced by $\mathrm{T}$ and NK cells. Subsequently, IFN- $\gamma$ binds to its receptor, interferon-gamma receptor (IFNGR), and activates the Janus kinase signal transducer and activator of 
Table 1 Regulators of PD-L1

\begin{tabular}{|c|c|c|c|c|c|c|}
\hline \multirow{2}{*}{$\begin{array}{l}\text { Regulatory Types } \\
\text { Regulation of PD- } \\
\text { L1 at DNA level }\end{array}$} & \multirow{2}{*}{$\begin{array}{l}\text { Regulators } \\
\text { Genomic } \\
\text { alteration }\end{array}$} & \multirow{2}{*}{\multicolumn{2}{|c|}{$\begin{array}{l}\text { PD-L1 } \\
\text { amplifications }\end{array}$}} & \multicolumn{2}{|l|}{ Cancer types } & \multirow{2}{*}{$\begin{array}{l}\text { References } \\
20-23,25, \\
26]\end{array}$} \\
\hline & & & & Upregulation & $\begin{array}{l}\text { Hodgkin's lymphoma, SCLC, NSCLC, EBV-positive gastric } \\
\text { cancer, and squamous cell carcinoma of the oral cavity. }\end{array}$ & \\
\hline & & translocation & & Upregulation & mediastinal large B cell lymphoma & [24] \\
\hline & Epigenetic & histone & HDAC3 & Upregulation & drug-resistant cancer & {$[27]$} \\
\hline & & $d e$ & HDAC6 & Upregulation & melanoma & [28] \\
\hline & & $\begin{array}{l}\text { methylation } \\
\text { at CpG sites }\end{array}$ & DNA & Downregulation & melanoma, NSCLC, HNSCC, and CRC & [29-32] \\
\hline & & H3K4me3 & & Upregulation & pancreatic cancer and breast cancer & {$[33,34]$} \\
\hline & & H3K27me3 & & Downregulation & $\mathrm{HCC}$ & [35] \\
\hline \multirow{33}{*}{$\begin{array}{l}\text { Regulation of PD- } \\
\text { L1 at RNA level }\end{array}$} & Inflammatory & $\mathrm{IFN}-\gamma$ & & Upregulation & sarcoma, colon cancer, melanoma, and NSCLC & [36-38] \\
\hline & & IFN-a, IFN- $\beta$ & & Upregulation & melanoma & [39] \\
\hline & & TLR4 & & Upregulation & bladder cancer & {$[40,41]$} \\
\hline & & TLR3 & & Upregulation & neuroblastoma & [42] \\
\hline & & $\mathbb{I L}-17$ & & Upregulation & prostate cancer and colon cancer & [43] \\
\hline & & IL-4 & & Upregulation & $\mathrm{RCC}$ & [44] \\
\hline & & IL-27 & & Upregulation & ovarian cancer; Prostate cancer; NSCLC & [45] \\
\hline & & IL-6 & & Upregulation & prostate cancer; HCC; GBM; NSCLC & [46-49] \\
\hline & & $\mathrm{IL}-10$ & & Upregulation & oscC & [50] \\
\hline & & TGF- $\beta$ & & Upregulation & NSCLC & {$[51,52]$} \\
\hline & Aberrant & EGFR & & & NSCLC and LUAD & {$[53,54]$} \\
\hline & $\begin{array}{l}\text { Oncogenic } \\
\text { signaling }\end{array}$ & ERK & & & $\begin{array}{l}\text { multiple myeloma, breast cancer, NSCLC, bladder } \\
\text { cancer, pancreatic cancer, and lymphoma }\end{array}$ & {$[55-60]$} \\
\hline & & PTEN & & Downregulation & breast cancer & {$[58,61-69]$} \\
\hline & & PTEN/PI3K/AK & & Upregulation & $\begin{array}{l}\text { gastric cancer, NSCLC, CRC, glioma, melanoma, HNSCC, } \\
\text { CRC, and Her2- amplified cancer }\end{array}$ & [70] \\
\hline & & JAK-STAT & & Upregulation & breast cancer and NSCLC & {$[23,71,72]$} \\
\hline & & $N F-K B$ & & Upregulation & NSCLC, breast cancer, melanoma & [73-77] \\
\hline & & $\mathrm{HIF-1}$ & & Upregulation & LUAD, RCC & [78-84] \\
\hline & & MYC & & Upregulation & $\begin{array}{l}\text { melanoma, NSCLC, ESCC, leukemia, lymphoma, and } \\
\text { pancreatic cancer }\end{array}$ & {$[85-92]$} \\
\hline & & & & Downregulation & $\mathrm{HCC}$ & [93] \\
\hline & & ALK & & Upregulation & NSCLC, lymphoma, LUAD & {$[79,94-97]$} \\
\hline & & Met & & Upregulation & NSCLC & [98-100] \\
\hline & & BRD4 & & Upregulation & ovarian cancer, lymphoma & {$[101,102]$} \\
\hline & & DSB & & Upregulation & osteosarcoma, NSCLC, and prostate cancer & [103] \\
\hline & & $A P-1$ & & Upregulation & Hodgkin's lymphoma & {$[104,105]$} \\
\hline & & $\mathrm{SHH}$ & & Upregulation & gastric cancer & {$[106]$} \\
\hline & & P53 & & Upregulation & melanoma, NSCLC, mesothelioma, GBM & {$[107-110]$} \\
\hline & $\begin{array}{l}\text { Epigenetic } \\
\text { regulation }\end{array}$ & $\begin{array}{l}\text { N6-methylad } \\
\text { (m6A) methy }\end{array}$ & $\begin{array}{l}\text { enosine } \\
\text { lation }\end{array}$ & Downregulation & HNSCC, LUAD, and colon cancer & [111-114] \\
\hline & & miR-34a & & Downregulation & AML and lymphoma & {$[115,116]$} \\
\hline & miRNA & miR-142-5p & & Downregulation & pancreatic cancer & [117] \\
\hline & & miR-93, miR- & 106b & Downregulation & pancreatic cancer & [118] \\
\hline & & miR-138-5p & & Downregulation & CRC & [119] \\
\hline & & miR-217 & & Downregulation & laryngeal cancer & [120] \\
\hline & & miR-200 & & Downregulation & NSCLC and gastric cancer & {$[121,122]$} \\
\hline
\end{tabular}


Table 1 Regulators of PD-L1 (Continued)

\begin{tabular}{|c|c|c|c|c|c|}
\hline \multirow[t]{2}{*}{ Regulatory Types } & \multirow[t]{2}{*}{ Regulators } & \multirow{2}{*}{ miR-152 } & \multicolumn{2}{|l|}{ Cancer types } & \multirow{2}{*}{$\begin{array}{l}\text { References } \\
{[122]}\end{array}$} \\
\hline & & & Downregulation & gastric cancer & \\
\hline & & miR-570 & Downregulation & gastric cancer & [123] \\
\hline & & $\operatorname{miR}-17-5 p$ & Downregulation & melanoma & [124] \\
\hline & & $\begin{array}{l}\text { miR-15a, miR-193a, } \\
\text { miR-16 }\end{array}$ & Downregulation & malignant pleural mesothelioma & [125] \\
\hline & & miR-148a-3p & Downregulation & CRC & [126] \\
\hline & & miR-873 & Downregulation & breast cancer & [127] \\
\hline & & miR-424(322) & Downregulation & ovarian cancer & [128] \\
\hline & & miR-214 & Downregulation & lymphoma & [129] \\
\hline & & miR-497-5p & Downregulation & $\mathrm{RCC}$ & [130] \\
\hline & & $\operatorname{miR}-140$ & Downregulation & NSCLC & [131] \\
\hline & $\begin{array}{l}\text { Indirect } \\
\text { regulation by }\end{array}$ & $\begin{array}{l}\text { miR-20, miR-21, miR- } \\
\text { 130b }\end{array}$ & Upregulation & CRC & [132] \\
\hline & $\mathrm{mll}$ & miR-23a-3p & Upregulation & $\mathrm{HCC}$ & [133] \\
\hline & & miR-18a & Upregulation & cervical cancer & [134] \\
\hline & & miR-197 & Downregulation & $\mathrm{NSCLC}$ & [135] \\
\hline & & miR-145 & Downregulation & ovarian cancer & [136] \\
\hline & mRNA & RAS & Upregulation & RAS mutant cancer & [137] \\
\hline & ation & Angiotensin ॥ & Upregulation & NSCLC & [138] \\
\hline & & G3BP2 & Upregulation & breast cancer and GBM & [139] \\
\hline \multirow{15}{*}{$\begin{array}{l}\text { Regulation of PD- } \\
\text { L1 at protein } \\
\text { level }\end{array}$} & Ubiquitination & $c-C b l$ and $\mathrm{Cbl}-\mathrm{b}$ & Downregulation & NSCLC & [140] \\
\hline & & USP22 & Upregulation & $\mathrm{HCC}$ & [141] \\
\hline & & USP9X & Upregulation & OsCC & [142] \\
\hline & & UCHL1 & Upregulation & NSCLC & [143] \\
\hline & & CMTM6 & Downregulation & $\begin{array}{l}\text { melanoma, NSCLC, CRC, thyroid cancer, pancreatic } \\
\text { cancer, breast cancer }\end{array}$ & {$[144,145]$} \\
\hline & & CMTM4 & Downregulation & NSCLC and melanoma & [145] \\
\hline & & CDK4 & Downregulation & cervical cancer and breast cancer & [146] \\
\hline & & CSN5 & Downregulation & breast cancer & [147] \\
\hline & Phosphorylation & Tyr112 & Upregulation & $\mathrm{HCC}$ & [148] \\
\hline & & S195 & Downregulation & breast cancer & [149] \\
\hline & & GSK3 $\beta$ & Downregulation & breast cancer & {$[150,151]$} \\
\hline & Glycosylation & N192/200/219 & Upregulation & breast cancer & [150] \\
\hline & & STT3 & Upregulation & cancer stem cell & [152] \\
\hline & & FKBP51s & Upregulation & glioma & [153] \\
\hline & Palmitoylation & C272 & Upregulation & breast cancer and colon cancer & {$[154,155]$} \\
\hline \multirow{2}{*}{$\begin{array}{l}\text { Extracellular PD- } \\
\text { L1 }\end{array}$} & exosome & & Upregulation & HNSCC, breast cancer, and melanoma & [156-159] \\
\hline & soluble protein & & Upregulation & NSCLC & [160-163] \\
\hline \multirow[t]{4}{*}{ Biomarkers } & TMB & & Upregulation & multiple cancer types & [164] \\
\hline & MSI & & Upregulation & multiple cancer types & [165] \\
\hline & TIL & & Upregulation & multiple cancer types & [166] \\
\hline & Intratumor hetero & ggeneity & Upregulation & multiple cancer types & [167] \\
\hline
\end{tabular}


transcription (JAK-STAT) signaling pathway via STAT1. Consequently, it upregulates expression of transcription factors, preferentially the interferon-responsive factors (IRFs) [39, 184]. As the vital downstream signaling protein of STAT1, IRF1 critically mediates IFN- $\gamma$-induced PD-L1 [185]. IRF1-deficient mouse models in colon cancer and melanoma showed inhibited tumor growth and upregulation of PD-L1 expression [37]. Moreover, PDL1 expression is highly correlated with IRF1 in lung cancer [38]. IFN- $\gamma$-induced accumulation of IRF1 saturates STXBP6 and stimulates nuclear translocation of IRF1 that inhibits STXBP6 expression and triggers the migration of more IRF1 to the nucleus; this positive feedback loop regulates PD-L1 transcription [186]. IRE1/2 constitutes the binding sites of IRF1 in the CD274 promoter, regulating PD-L1 transcription in HCC [187]. Furthermore, as a major component of the AK-STAT-IRF1 pathway, JAK1 and JAK2 mutations downregulate PDL1 expression and reduce the efficacy of anti-PD-1 therapy [188]. Therefore, besides PD-1/ PD-L1 axis, tumor cells might develop alternative escaping immune surveillance approaches [188].

In addition to IFN- $\gamma$, type I interferons, IFN- $\alpha$, IFN- $\beta$ could stimulate PD-L1 expression. Notably, type I interferons regulate PD-L2 expression compared to PD-L1 expression in melanoma [39]. Lipopolysaccharide (LPS) activates toll-like receptor (TLR) 4-nuclear factor kappalight-chain-enhancer of activated B cells (NF-kB)-IFN- $\gamma$ signaling cascade and subsequently induces PD-L1 expression in bladder cancer $[40,41]$. Similarly, polyinosinicpolycytidylic acid (poly (I: C))-stimulated TLR3 upregulates the expression of PD-L1 in neuroblastoma $[4,42]$.

Other inflammatory stimuli including IL-1b, IL-4, IL-6, IL-10, IL-12, IL-17, IL-27, tumor necrosis factor- $\alpha$ (TNF$\alpha$ ), and transforming growth factor- $\beta$ (TGF- $\beta$ ) have also been linked to PD-L1 induction. For instance, IL-4 and TNF- $\alpha$ exert synergistic effects on the PD-L1 induction in renal cell carcinoma (RCC) by activating signaling molecules, including NF-кB, IкB, and STAT6 [44]. Blockade of PD-L1 was accompanied by a downregulation of IL-10 in dendritic cells and monocytes [189]. Besides, the IL-10 abundance directly correlated with PD-L1 expression on TAMs in OSCC [50]. IL-12 demonstrated a dual impact on PD-L1 regulation, i.e., upregulating PD-L1 expression in monocyte-derived macrophages, whereas downregulating PD-L1 expression in THP-1-derived macrophages [190]. IL-17 mediates PD-L1 induction in monocytes [191]. IL-17 and TNF- $\alpha$ individually upregulate PD-L1 expression by activating NF- $\mathrm{KB}$ signaling in prostate cancer, as well as NF- $\mathrm{kB}$ and ERK1/2 signaling in colon cancer [43]. IL-1b and IL-27 upregulate the expression of PD-L1 in dendritic cells [192]. Moreover, IL-27 promotes PD-L1 expression via phospho-STAT1 and phospho-STAT3 [45].
IL-6-triggered JAK-STAT3 signaling pathway upregulated PD-L1 expression in prostate cancer, which IL-6expressing tumor is resistant to NK cell-mediated immune action [46]. Besides, IL-6 induces activation of JAK2/STAT3/c-MYC signaling cascade that enhances miR-25-3p transcription and suppresses protein tyrosine phosphatase receptor type O (PTPRO), where the depletion of PTPRO further causes PD-L1 secretion by impairing the activity of JAK2/STAT1 and JAK2/ STAT3/c-MYC signaling pathways [47]. Additionally, glioblastoma (GBM)-derived IL-6/STAT3 signaling pathway correlated with myeloid PD-L1 expression [48]. IL6-MEK/ERK signaling pathway promoted the upregulation of PD-L1 expression, causing an immune escape in lung cancer [49]. Previous studies demonstrated that HCC-CAF-derived IL6 activates the STAT3-PDL1 signaling cascade [193]. Further, IL6 blockade upregulated PD-L1 expression in melanoma, where the IL6PD-L1 axis was described as a rational immunosuppressive target for anti-PD-L1 therapy [194].

TGF- $\beta$ positively regulates the expression of PD-L1. Tumor-infiltrating CD8+ T cells produced TGF- $\beta$ and subsequently upregulated PD-L1 expression [195]. TGF$\beta$ upregulated PD-L1 expression in dendritic cells of lung cancer [51]. Further, TGF- $\beta$ upregulated PD-L1 expression via Smad-binding elements in NSCLC cells [52]. Nevertheless, several studies revealed that TGF- $\beta$ repressed PD-L1 expression in monocytes or proximal renal tubular epithelial cells $[196,197]$.

\section{Aberrant oncogenic signaling}

Oncogenic signaling pathways regulate tumor cell survival, proliferation, and progression. Accumulating evidence indicates that certain oncogenic signaling pathways promote PD-L1 expression.

\section{Epidermal Growth Factor Receptor (EGFR)}

EGFR signaling regulates tumor proliferation, progression, angiogenesis, evasion of apoptosis, and evasion of immunity [198]. EGFR mutation in epithelial cells of NSCLC induced PD-L1 expression, where EGFR inhibitors significantly lowered PD-L1 expression in NSCLC with activated EGFR. Moreover, anti-PD-1 therapy enhanced effector T-cell function and suppressed tumor proliferation in EGFR-driven LUAD [53]. These findings indicate that EGFR signaling caused immune escape. A retrospective study reported a conflicting result, i.e., concurrent upregulation of PD-L1 expression and tumorinfiltrating CD8+ $\mathrm{T}$ cells were rarely observed in EGFRdriven NSCLC. Besides, NSCLC with EGFR mutations was resistant to PD-L1 inhibitors [54]. Notably, NSCLC patients receiving standard EGFR-tyrosine kinase inhibitors (TKIs) treatment showed downregulated EGFRinduced PD-L1 expression and upregulated IFN- $\gamma$ - 
induced PD-L1 expression. Summarily, PD-L1 expression was dynamically regulated by diverse factors [199].

\section{Extracellular signal-regulated kinase (ERK)}

Mitogen-activated protein kinase (MAPK), also termed extracellular signal-regulated kinase (ERK), promotes cancer development in multiple cancer types [200]. Previous studies confirmed that PMA-activated or variant of MEK (MEK-DD)-activated MEK-ERK signaling regulate PD-L1 expression via IFN- $\gamma$-induced STAT1 phosphorylation in multiple myeloma and triple-negative breast cancer (TNBC) $[55,56]$. Similarly, in NSCLC, activation of the MAPK signaling pathway was inferred by RAS or MEK activation positively correlated with CD274 transcriptional level [57]. CD274 gene expression was also upregulated by activation of EGF-MAPK signaling [57]. MAPK signaling primarily targets JUN that subsequently cooperates with STAT3 upregulating PDL1 expression in BRAF inhibition (BRAFi)-resistant melanoma and NSCLC, where the signaling cascade is reversible by MEK inhibition (MEKi) [58, 59].

Further, p38-MAPK, another MAPK signaling cascade, has a positive regulation on PD-L1 expression in dendritic cells, multiple myeloma, bladder cancer, and lymphoma [4]. Notably, MEKi could abrogate the upregulated PD-L1 expression stimulated by TLR ligands [4]. Furthermore, the EGFR-MAPK signaling cascade, activated by myeloid cells, could upregulate PD-L1 expression in pancreatic cancer [60].

\section{PTEN/PI3K/AKT signaling pathway}

PTEN regulates suppressing PI3K-AKT signaling cascade in multiple cancer types [201]. In TNBC expressing PD-L1, PTEN deficiency was frequently observed, and its knockdown upregulated the expression of PD-L1 [70]. In addition, the activated PI3K-AKT signaling pathway caused an upregulated expression of PD-L1 in gastric cancer [61]. Moreover, the PI3K-AKT signaling pathway upregulated IFN- $\gamma$-stimulated PD-L1 expression in NSCLC, CRC, glioma, breast cancer, and melanoma [62-66], while PI3K inhibition downregulated PDL1 expression in HNSCC cells, CRC cells, melanoma cells, and Her2-amplified cancer cells [58, 67-69]. Besides, as a vital downstream of the PI3K-AKT signaling pathway, mTOR can be inhibited by rapamycin to lower the expression of PD-L1 in NSCLC [63].

Specifically, miR-20, miR-21, and miR-130b enhanced PD-L1 expression in CRC by targeting PTEN [132]. miR-23a-3p promoted PD-L1 expression in HCCderived macrophages by repressing PTEN [133]. Similarly, miR-18a upregulated PD-L1 expression by targeting PTEN, WNK2, and SOX6, which activates PI3K/ AKT, MEK/ERK Wnt/ $\beta$-catenin signaling pathways as well as the inhibitors of the p53 signaling pathway in cervical cancer [134].

\section{JAK-STAT signaling pathway}

JAK-STAT signaling pathway mediates most anti-tumor immune responses, including tumor cell identification and tumor-driven immune evasion [202]. As mentioned in the inflammatory signaling, STAT3 phosphorylation enhanced PD-L1 transcription while STAT inhibition hampered PD-L1 transcription. A novel STAT3 mutation, p.E616K triggered a robust binding of STAT3 to PD-L1 promoter and subsequently increased PD-L1 transcription [203]. Moreover, JAK and STAT3 amplification enhanced PD-L1 expression in TNBC and NSCL C $[23,71]$. Ataxia Telangiectasia Mutated (ATM) upregulated PD-L1 expression through activated JAK/STAT3 signaling pathway in lung cancer with cisplatin resistance [72]. Besides, miR-197 downregulated PD-L1 expression by directly activating the CKS1B-STAT3 signaling cascade in NSCLC [135].

\section{NF-KB family}

NF- $\kappa B$ cooperates with multiple oncogenic signaling pathways during cancer initiation and progression [204] and is increasingly related to high PD-L1 expression [73, 177, 205-207]. Immune escape was caused by activation of the NF-kB-PD-L1 axis [208]. The overexpression of MUC1-C caused an increased binding of NF-kB p65 to CD274 promoter and subsequently increased PD-L1 transcription in NSCLC [74]. Likewise, the stimulator of IFN genes (STING)/TANK-binding kinase-1 (TBK1) signaling pathway recruit NF-kB p65 to $\mathrm{CD} 274$ promoter and activates both NF- $k B$ and IRF3, contributing to PDL1 transcription [75]. NF- $\mathrm{kB}$ also drives ZEB1 expression, which serves as a transcription factor that mediates EMT [209]. The NF-kB-stimulated ZEB1 expression further suppressed miR-200-induced differentiation of EMT and enhanced PD-L1 expression [76]. Accumulated reactive oxygen species (ROS) activated NF-кB signaling in triple-negative breast cancer [77]. Additionally, inhibited NF-kB pathway suppresses IFN- $\gamma$-induced PDL1 expression in melanoma cells [73].

\section{Hypoxia-inducible factor-1 (HIF-1)}

Hypoxia creates a permissive tumor microenvironment (TME) that facilitates tumor metastasis and immune escape [210]. The cellular colocalization of HIF-1 $\alpha$ and PD-L1 was observed in various cancer cell types [78]. The hypoxia-induced PD-L1 expression was suppressed after HIF-1 $\alpha$ was blocked using glyceryl trinitrate (GTN) [78]. Besides, HIF-1 $\alpha$ regulated PD-L1 expression in LUAD and myeloid-derived suppressor cells (MDSCs) $[79,80]$. HIF- $1 \alpha$ could also activate NF- $\mathrm{kB}$ signaling by inducing transcription factor IKK $\beta$ through the hypoxia 
response element (HRE) [81]. In turn, NF- $\mathrm{kB}$ activated HIF- $1 \alpha$ by directly binding to the HIF- $1 \alpha$ promoter, which the reinforced NF- $\mathrm{kB}$ and HIF- $1 \alpha$ mutually sustained PD-L1 expression [82]. Moreover, EZH2 upregulates PD-L1 expression through a HIF-1 $\alpha$-dependent manner [83]. HIF- $2 \alpha$ also interacts with the HRE in the $P D-L 1$ promoter and regulates $P D-L 1$ expression in $R C C$ [84].

MYC

Overexpressed oncogene, MYC, is frequently observed in most human cancers and promotes tumorigenesis [211]. Inactivation of MYC downregulated $P D-L 1$ expression in melanoma, NSCLC, esophageal squamous cell carcinoma (ESCC), leukemia, lymphoma, and pancreatic cancer [85-90]. Furthermore, chromatin immunoprecipitation (ChIP)-seq assay revealed that $M Y C$ binds to $P D-L 1$ promoter [86], indicating that MYC directly regulates PD-L1 expression transcriptionally. Cyclin-dependent kinase 7 (CDK7)/MYC/PD-L1 signaling cascade have been demonstrated to enhance PD-L1 expression, and the CDK7 inhibitor, THZ1, downregulated PD-L1 expression by suppressing MYC activity in NSCLC [91]. MYC also critically mediated S100A9induced PD-L1 expression [92]. In contrast, MYC negatively regulated IFN- $\gamma$-induced $P D-L 1$ expression in HCC [93]. In addition, MYC inhibition hampered tumor growth, enhanced tumor immune cell infiltration, upregulated $P D-L 1$ expression, and sensitized anti-PD1 immune response [212]. Additionally, miR-145 downregulated the expression of $P D-L 1$ by repressing $c$ $M Y C$ in ovarian cancer [136].

\section{Bromodomain-containing protein 4 (BRD4)}

As an essential member of the bromodomain and extra terminal (BET) family, BRD4 is known in cancer as a super-enhancer and regulator of oncogenes [213]. BRD4 directly targets CD274 since the ChIP-seq assay revealed a positive correlation between CD274 promoter and BRD4 in ovarian cancer [101]. Besides, BET inhibition downregulated PD-L1 expression and suppressed tumor progression [101]. BET inhibitor (BETi), JQ1, also limited PD-L1 transcription by decreasing BRD4 occupancy at CD274 promoter without changes in MYC occupancy in lymphoma [102]. Conversely, JQ1 was reported to decrease PD-L1 expression by downregulating MYC [86]. The contradictory role of BETi needs to be further verified.

\section{Anaplastic lymphoma kinase (ALK)}

Oncogenic ALK signaling resulting from chromosomal rearrangements is present in NSCLC [214]. Previous studies confirmed that NPM-ALK fusion protein promoted PD-L1 expression through STAT3 signaling and
MEK-ERK signaling in lymphomas [94, 95]. Similarly, in NSCLC, echinoderm microtubule-associated protein-like 4 (EML4)-ALK fusion gene was associated with higher PD-L1 expression. EML4-ALK upregulates PD-L1 expression as well as activates downstream mediators, ERK, and AKT in NSCLC [79], STAT3, and HIF- $1 \alpha$ in LUAD [96]. Besides, ALK correlated positively with PDL1 expression in lymphoma [97].

\section{Met}

Met oncogene initiates tumor transformation, fosters tumor growth, and modulates the self-renewal ability of cancer stem cells [215]. In NSCLC, amplification of Met was positively related to PD-L1 expression $[98,99]$. Met suppression using Met inhibitors or Met activation using hepatocyte growth factor (HGF) upregulated or downregulated PD-L1 expression in different human cancer cell lines, respectively [100].

\section{DNA double-strand break (DSB) repair signaling pathway} Exogenous cellular stress stimulates PD-L1 expression in cancer, where DSB represents the most vital type of genotoxic stress. The upregulated PD-L1 expression in osteosarcoma, lung cancer, and prostate cancer in response to DSB required the activation of STAT1/3-IRF1 signaling pathway by ATM/ATR/Chk1 kinases [103]. Moreover, depleted BRCA2 or Ku80 enhanced PD-L1 expression in the X-rays-induced DSB signaling cascade [103].

\section{Activator protein-1 (AP-1)}

As a dimeric transcription factor, AP-1 regulates cell life and death and was recently identified as a potent oncogene [216]. AP-1 containing PD-L1 enhancer element increased PD-L1 promoter activity and elevated PD-L1 transcription in Hodgkin's lymphoma [104]. EBVencoded latent membrane protein-1 (LMP1) previously triggered AP-1 activity in lymphoma [105]. In line with this finding, EBV-infected lymphoproliferative cancer was detected with high PD-L1 expression [104].

\section{Sonic hedgehog $(\mathrm{SHH})$ signaling pathway}

The SHH signaling pathway is reactivated in gastric cancer and induces PD-L1 expression [217]. H. pylori significantly stimulated PD-L1 expression by mediating SHH signaling pathway in gastric cancer [106]. In a clinical trial of basal cell carcinoma, patients experiencing SHH pathway-directed therapy exhibited a better response to anti-PD-1 therapy [218].

\section{P53}

P53 is another classical oncogene and therapeutic target in cancer [219] regulating IFN- $\gamma$-stimulated PD-L1 expression in melanoma by JAK2 overexpression [107]. 
p53 regulates PDL1 expression via miR-34 in NSCLC [108] and via miR-320a in mesothelioma [109]. Notably, nanomedicine with p53 significantly upregulated PDL1 expression in GBM [110].

\section{Epigenetic regulation}

N6-methyladenosine (m6A) methylation is the most common mRNA modification and reportedly regulates carcinogenesis. Based on the large-scale bioinformatics analysis, m6A regulators correlated with PD-L1 expression in HNSCC and lung adenocarcinoma (LUAD) [111, 112]. m6A-binding protein YTHDF1 mediates m6A methylation, where the therapeutic efficacy of anti-PD-1 therapy is enhanced in YTHDF1-knockout mice [113]. Fat mass and obesity-associated protein (FTO) demethylates m6A, depleting FTO downregulated IFN- $\gamma$-induced PD-L1 expression in colon cancer [114].

\section{Regulation by microRNA (miRNA)}

miRNAs physiologically function as post-transcriptional regulators for gene expression [220], where miRNAs also regulate PD-L1 expression by binding to CD274 mRNA or affecting PD-L1 regulators. miR-513, suppressed by IFN- $\gamma$, directly binds to the 3' UTR of CD274 and suppresses PD-L1 expression [221]. Similarly, miR-513, enforced by TNF- $\alpha$ and IFN- $\gamma$, binds to the 3' UTR of CD274 and suppresses PD-L1 expression [222]. miR-34a also binds to $3^{\prime}$ UTR of CD274 and lowers PD-L1 expression in acute myeloid leukemia (AML) and lymphoma [115, 116]. Moreover, miR-142-5p [117], miR-93, and miR-106b [118] regulated PD-L1 expression in pancreatic cancer. miR-138-5p regulated PD-L1 expression in CRC [119]. miR-217 regulated PD-L1 expression in laryngeal cancer [120]. miR-200 regulated PD-L1 expression in NSCLC and gastric cancer [121, 122]. miR-152 [122] and miR-570 [123] regulated PD-L1 expression in gastric cancer. miR-17-5p regulated PD-L1 expression in melanoma [124]. miR-15a, miR-193a, and miR-16 regulated PD-L1 expression in malignant pleural mesothelioma [125]. miR-148a-3p regulated PD-L1 expression in CRC [126]. miR-873 regulated PD-L1 expression in breast cancer [127]. miR-424 (322) regulated PD-L1 expression in ovarian cancer [128]. miR-214 regulated PDL1 expression in lymphoma [129]. miR-497-5p regulated PD-L1 expression in RCC [130]. miR-140 regulated PDL1 expression in NSCLC [131]. These miRNAs have all been identified as critical suppressors of PD-L1 expression.

Notably, post-transcriptional regulators miRNAs also regulated CTLA-4 expression; for example, miR-155 increased the $\mathrm{T}$ helper $(\mathrm{TH})$ cell proliferation through downregulating CTLA-4 expression [223]. circRNA0003528 promoted CTLA-4 expression downregulating miR-224-5p, miR-324-5p and miR-488-5 $\mathrm{p}^{193}$. Moreover,
3'-UTR variation affected the repressive ability of miR302a in inhibiting CTLA-4 expression [224].

\section{Stability of PD-L1 mRNA}

The structural disruption in the 3 ' untranslated regions (UTR) influences CD274 mRNA stability causing elevated PD-L1 expression [225]. RAS, downstream of MEK signaling, of which activation phosphorylated tristetraprolin (TTP) and inhibited TTP-mediated AU-rich element (ARE)-binding to the 3' UTR of PD-L1 mRNA via kinase MK2, which stabilized CD274 mRNA and consequently elevated PD-L1 expression [137]. Similarly, Angiotensin II stabilized CD274 mRNA and upregulated PD-L1 expression in NSCLC via human antigen $R$ (HuR), another ARE-binding protein [138]. A recent study also confirmed that GTPase-activating protein (SH3 domain)-binding protein 2 (G3BP2) stabilized PDL1 mRNA through its RNA recognition motif and upregulated PD-L1 expression under stress in breast cancer and GBM [139].

\section{Transcriptional regulation of CTLA-4}

Studies exploring the transcriptional regulation of CTLA-4 are limited. The nuclear factor of activated Tcells (NFAT) binds to the CTLA-4 promoter and promotes CTLA-4 transcription (Fig. 3, Table 2). Furthermore, the mutated NFAT site abolished the activity of the CTLA-4 promoter, where inhibitors of NFAT also suppressed CTLA-4 transcription [226]. Forkhead box P3 (Foxp3) is another transcription factor interacting with NFAT at CTLA-4 promoter and activated CTLA-4 transcription [227]. The transcriptional activity of Foxp3 was reported be reinforced by transcription factors including GATA-1, Lef1, Eos, IRF4, and Satb1 [242]. CD28 has been recommended for its counteraction with CTLA-4 [228]. Stimulation with IL-1 $\alpha$, IFN- $\gamma$, IL-2, and inhibition of CD28 have all been proved to promote CTLA-4 expression [229], while IL-4, IL-6, IL-7, and IL12 only showed limited ability in inducing CTLA-4 expression [230]. The interaction between CTLA-4 and STAT5 was proved to critically mediate CTLA-4 signaling [231]. STAT1, c-Fos, C-MYC, and Bcl-2 positively correlate with CTLA-4 expression in chronic lymphocytic leukemia (CLL) [232]. Kinase PKC- $\eta$ also regulated CTLA-4 expression, and the CTLA-4-PKC- $\eta$ axis was essential for Treg function [233].

\section{Regulation of PD-L1 at protein level}

Post-translational regulation at the protein level is the eventual step where the gene expression level is modulated. Among the multiple post-translational modulators, ubiquitination, phosphorylation, glycosylation, and palmitoylation regulate PD-L1 expression. 


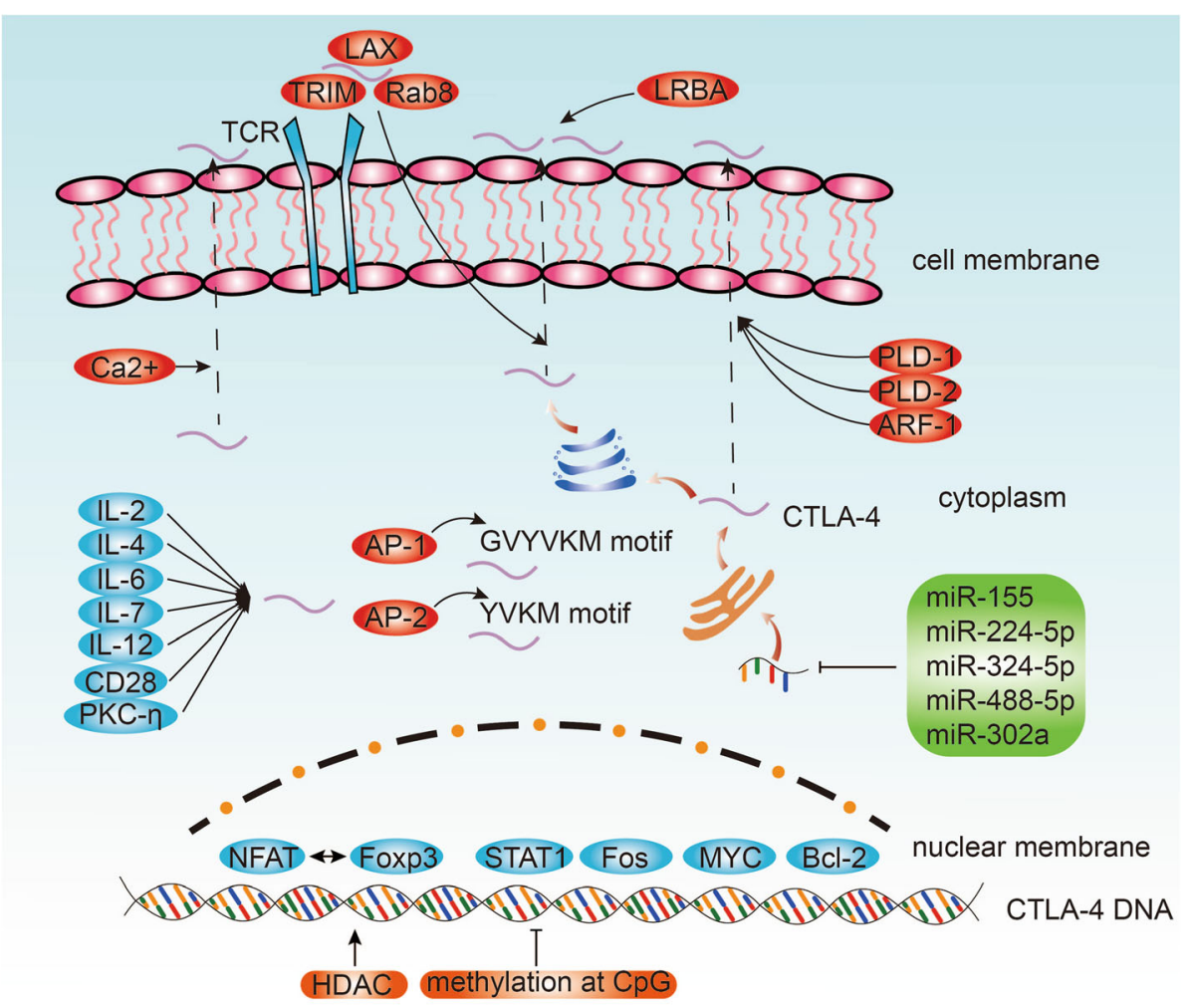

Fig. 3 Regulatory mechanisms of CTLA-4. CTLA-4 expression is regulated at RNA level (transcriptional regulation, direct regulation by miRNA) and DNA level (epigenetic regulation). Localization within the cell also regulate CTLA-4 expression.

\section{Ubiquitination}

The Casitas B-lineage lymphoma (Cbl) family has three major isoforms, c-Cbl, Cbl-b, and $\mathrm{Cbl}-\mathrm{c}$, among which $\mathrm{c}-\mathrm{Cbl}$ and Cbl-b with a ubiquitin-associated (UBA) domain suppressed PD-L1 expression after inhibiting PI3K/Akt, JAK-STAT, and MEK/Erk signaling pathways in NSCLC [140]. Additionally, ubiquitin-specific peptidase 22 (USP22) in HCC [141], ubiquitin-specific peptidase 9, X-linked (USP9X) in OSCC [142], and ubiquitin C-terminal hydrolase L1 (UCHL1) in NSCLC [143] deubiquitinate and upregulate the PD-L1 expression.

As a ubiquitously expressed protein, CMTM6 binds PDL1 either at the plasma membrane or in recycling endosomes, repressing lysosome-mediated degradation of PD$\mathrm{L} 1$ and upregulating protein half-time of PD-L1 without affecting the transcription level of PD-L1 [144, 145]. Notably, CMTM4 shares a similar function with CMTM6 [145].

Besides, PD-L1 expression is negatively regulated by cyclin-dependent kinase 4 (CDK4). CDK4 indirectly promotes ubiquitination of PD-L1 by phosphorylating the adaptor protein of Cullin 3 (CUL3), SPOP, an E3 ubiquitin ligase for PD-L1 [146]. Inhibition of CDK4/6 upregulated PD-L1 expression [146]. Moreover, NF-кB p65induced COP9 signalosome 5 (CSN5) stabilized PD-L1 expression by inhibiting ubiquitination of $\mathrm{PD}-\mathrm{L} 1$ via TNF- $\alpha$ [147].

\section{Phosphorylation}

IL-6/JAK1 signaling cascade phosphorylates PD-L1 Tyr112 that recruits the endoplasmic reticulumassociated N-glycosyltransferase, STT3A. Subsequently, STT3A catalyzes PD-L1 glycosylation and elevates PDL1 stability [148]. Moreover, metformin-activated AMPactivated protein kinase (AMPK) phosphorylates PD-L1 S195, which enriches aberrant PD-L1 glycosylation. Subsequently, the translocation of PD-L1 was hampered while the degradation of PD-L1 was enhanced [149]. Besides, glycogen synthase kinase $3 \beta$ (GSK3 $\beta$ ) downregulates PD-L1 expression by inducing phosphorylationdependent proteasome degradation via $\beta-\operatorname{TrCP}$ [150]. Inhibition of Met-mediated phosphorylation and activation of GSK3B downregulated PD-L1 expression [151].

\section{Glycosylation}

PD-L1 N192/200/219 glycosylation antagonized the formation of the complex comprising PD-L1, GSK3 $\beta$, and $\beta$-TrCP and stabilized PD-L1 [150]. Further, EGF stabilized PD-L1 by inactivating glycosylation-induced GSK3 $\beta$ [150]. Moreover, EMT promoted Nglycosyltransferase STT3 via $\beta$-catenin in cancer stemlike cells (CSCs). STT3 induced PD-L1 N-glycosylation, and eventually, EMT / $\beta$-catenin/STT3 signaling cascade upregulated PD-L1 expression [152]. Besides, FKBP51s 
Table 2 Regulators of CTLA-4

\begin{tabular}{|c|c|c|c|c|}
\hline \multicolumn{2}{|l|}{ Regulatory Types } & \multirow{2}{*}{$\begin{array}{l}\text { Regulators } \\
\text { HDAC }\end{array}$} & \multirow{2}{*}{$\frac{\text { CTLA-4 }}{\text { Upregulation }}$} & \multirow{2}{*}{$\begin{array}{l}\text { References } \\
{[181]}\end{array}$} \\
\hline Regulation of CTLA-4 at DNA level & Epigenetic regulation & & & \\
\hline & & methylation of DNA at CpG sites & Downregulation & [182] \\
\hline \multirow[t]{11}{*}{ Regulation of CTLA-4 at RNA level } & Transcriptional regulation & NFAT & Upregulation & [226] \\
\hline & & Foxp3 & Upregulation & {$[227]$} \\
\hline & & CD28 & Downregulation & [228] \\
\hline & & $\mathrm{IL}-1 \mathrm{a}, \mathrm{IFN}-\gamma$ & Upregulation & [229] \\
\hline & & $\mathrm{IL}-2$ & Upregulation & [230] \\
\hline & & STAT5 & Upregulation & [231] \\
\hline & & STAT1, c-Fos, c-MYC, and Bcl-2 & Upregulation & [232] \\
\hline & & PKC-n & Upregulation & [233] \\
\hline & Direct regulation by miRNA & miR-155 & Downregulation & [223] \\
\hline & & miR-224-5p, miR-324-5p and miR-488-5p & Downregulation & [234] \\
\hline & & miR-302a & Downregulation & [224] \\
\hline \multirow[t]{7}{*}{ Localization within the cell } & & AP-1 & Upregulation & {$[235]$} \\
\hline & & AP-2 & Upregulation & {$[236]$} \\
\hline & & $\mathrm{TCR}$ & Upregulation & [237] \\
\hline & & TRIM & Upregulation & {$[238,239]$} \\
\hline & & GTPases, PLD- 1, PLD-2, and ARF-1 & Upregulation & [240] \\
\hline & & LRBA & Upregulation & {$[241]$} \\
\hline & & $\mathrm{Ca}^{2+}$ & Upregulation & [237] \\
\hline
\end{tabular}

promoted PD-L1 expression by catalyzing glycosylation in gliomas [153].

\section{Palmitoylation}

Palmitoylation at C272 stabilized PD-L1 by blocking the ubiquitination of PD-L1 [154]. Further, DHHC3 catalyzed palmitoylation at C272, suppressing PD-L1 expression and promoting anti-tumor immune response [155].

\section{Extracellular PD-L1}

Besides intracellular interactions between various regulators and PD-L1, PD-L1 expression is also regulated when PD-L1 is secreted as exosomes and soluble proteins at the extracellular level.

\section{PD-L1 in the form of exosome}

Exosomal PD-L1 has been reported in various cancer types. Exosomal PD-L1 suppressed T cell activity and promoted tumor progression in HNSCC [156]. Accordingly, blockade of exosomal PD-L1 secretion enhanced T cell activity [157]. Similarly, bioactive exosomal PD-L1 promoted tumor growth while blockade of exosomal PD-L1 secretion enhanced the response rates of antiPD-L1 therapy in breast cancer [158]. Additionally, IFN$\gamma$ stimulates the secretion of exosomal PD-L1 in melanoma [159]. Notably, exosomal PD-L1 expression varied following the stage of anti-tumor immunity [159].

\section{PD-L1 in the form of soluble protein}

Soluble PD-L1 (sPD-L1) was relatively more enriched in the plasma in NSCLC, correlating with poor prognosis and suppressed $\mathrm{T}$ cell activity [160]. Besides, patients with high plasma sPD-L1 exhibited enhanced efficacy of anti-PD-L1 therapy [161]. The secretion of four sPD-L1 with spicing variants increased after IFN- $\alpha$, IFN- $\gamma$, and TNF- $\alpha$ treatment, subsequently suppressing $\mathrm{T}$ cell activity [162]. Similarly, the secretion of five PD-L1 with splicing variants was observed in NSCLC, among which sPD-L1 with v229 and v242 were related to poor antiPD-L1 response [163].

\section{Biomarkers indirectly regulate PD-L1 expression}

Tumor mutation burden (TMB) was positively associated with PD-L1 expression, where patients with high TMB showed improved efficacy of anti-PD-1 therapy [164]. Similarly, microsatellite instability (MSI) positively correlates with PD-L1 expression and predicts a better anti-PD-1 response [165]. Intratumor heterogeneity was also linked to PD-L1 expression [167]. Moreover, TIL abundance was confirmed to correlate with upregulated PD-L1 expression [166].

\section{Localization of CTLA-4 within the cell}

Notably, CTLA-4 is mainly localized in intracellular compartments with the minority of CTLA-4 detected on 
the cell surface. Therefore, summarizing the mechanisms by which CTLA-4 could be transported to the cell surface is important. Plasma membrane-associated clathrin adaptor protein 1 (AP-1) binds to the GVYVKM motif of CTLA-4 and subsequently maintains a steady level of intracellular CTLA-4 expression [235]. Likewise, after AP-2 binds to the YVKM motif of CTLA-4 or the FVKM motif of mutant CTLA-4, CTLA-4 was more localized in the cytoplasm and less accumulated on the $\mathrm{T}$ cell surface [236, 237]. The strength of the T cell receptor (TCR) signaling pathway determined the upregulated CTLA-4 expression at the immunological synapse [237]. Besides, the adaptor $\mathrm{T}$ cell receptor-interacting molecule (TRIM) binds to CTLA-4, forming a CTLA-4/TRIM/ LAX/Rab8 effector complex, which in turn mediates the augment of CTLA-4 expression on the surface of $\mathrm{T}$ cell $[238,239]$. The activity of guanosine triphosphatases (GTPases), phospholipase D (PLD)- 1, PLD-2, and ADP ribosylation factor (ARF)-1 were necessary for increased release of CTLA-4 to the surface of the T cell [240].
Lipopolysaccharide-responsive and beige-like anchor protein (LRBA) loss causes CTLA-4 degradation and suppresses CTLA-4 expression [241]. Additionally, CTLA-4 expression on the cell surface was rapidly upregulated via the upregulated intracellular calcium $\left(\mathrm{Ca}^{2+}\right)$ [237].

\section{Potential drug intervention on PD-L1 and CTLA-4}

As for PD-L1, multiple drugs exhibited efficacy in regulating PD-L1 expression (Fig. 4, Table 3). Metformin attenuated PD-L1 expression by phosphorylating oncogene YAP1 and inhibiting its entry in the nucleus, subsequently inducing the Hippo signaling pathway in CRC [243]. Further, Nanodrug (MS NPs), self-assembled from metformin and anticancer agent 7-ethyl-10-hydroxycamptothecin (SN38), was developed to suppress PDL1 expression, enhancing the anti-tumor effect of combined immunotherapy and chemotherapy in breast cancer [244]. PARP inhibitor (PARPi) upregulated PD-L1 expression by inactivating GSK3 $\beta$ and enhancing

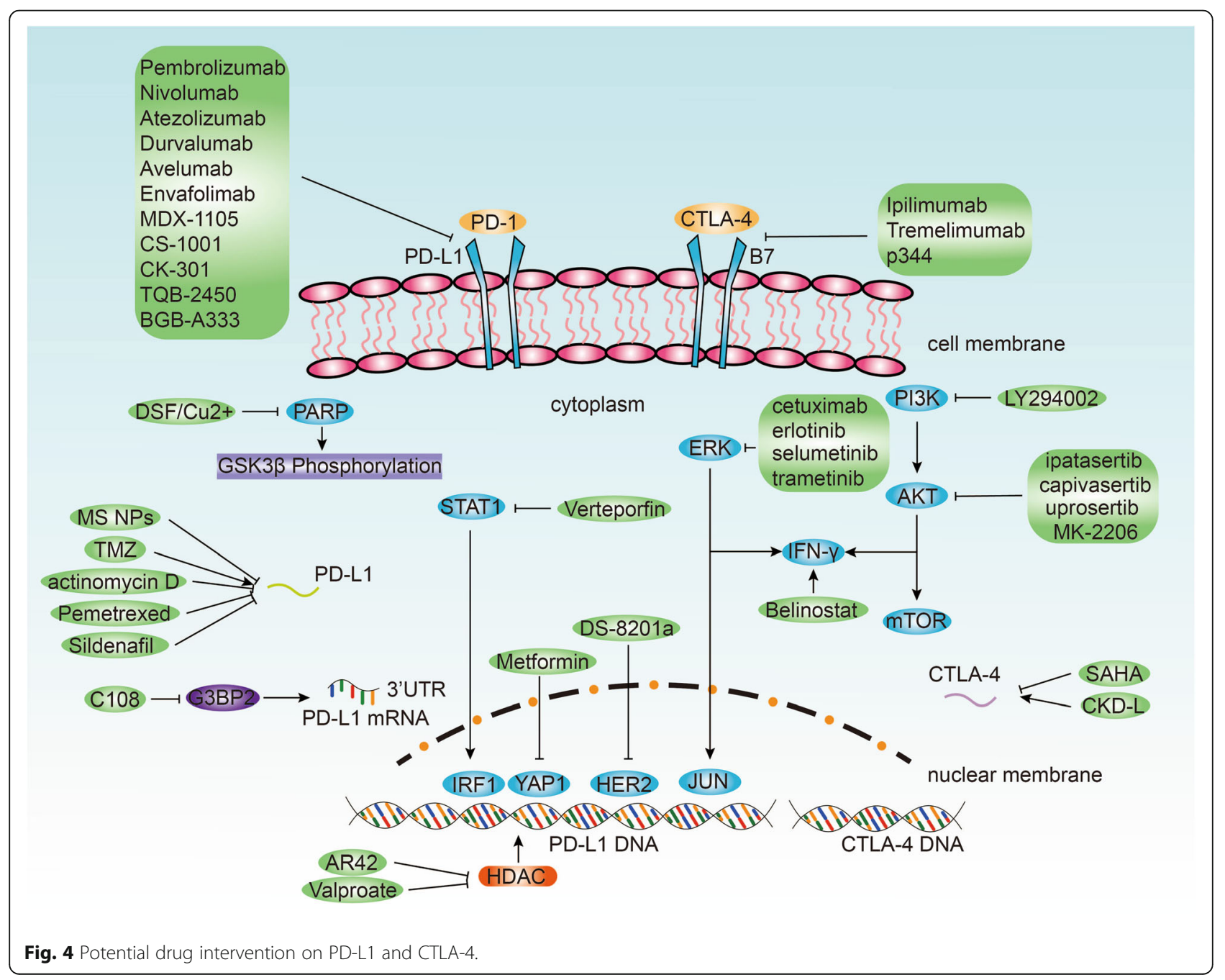


Table 3 Potential drugs intervening PD-L1 and CTLA-4

\begin{tabular}{|c|c|c|c|c|c|}
\hline \multicolumn{2}{|c|}{ Drugs } & \multirow{2}{*}{$\begin{array}{l}\text { Mechanism } \\
\text { phosphorylating } \\
\text { oncogene YAP1 }\end{array}$} & \multirow{2}{*}{$\begin{array}{l}\text { PD-L1 or } \\
\text { CTLA-4 } \\
\text { Downregulation }\end{array}$} & \multirow{2}{*}{$\begin{array}{l}\text { Cancer types } \\
\text { CRC }\end{array}$} & \multirow{2}{*}{$\begin{array}{l}\text { References } \\
{[243]}\end{array}$} \\
\hline $\begin{array}{l}\mathrm{PD}- \\
\mathrm{L} 1\end{array}$ & metformin & & & & \\
\hline & MS NPS & & Downregulation & breast cancer & [244] \\
\hline & PARPi & \multirow[t]{4}{*}{ inactivating GSK3 $\beta$} & Upregulation & breast cancer & {$[245]$} \\
\hline & TMZ & & Upregulation & GBM & {$[246]$} \\
\hline & actinomycin D & & Downregulation & GBM & [246] \\
\hline & $\begin{array}{l}\text { Pemetrexed and } \\
\text { sildenafil }\end{array}$ & & Downregulation & NSCLC & [247] \\
\hline & AR42 and valproate & $\begin{array}{l}\text { inhibiting histone } \\
\text { deacetylase }\end{array}$ & Downregulation & $\mathrm{NSCLC}$ & [247] \\
\hline & DSF/Cu ${ }^{2+}$ & $\begin{array}{l}\text { inactivating PARP1 and } \\
\text { phosphorylating } \\
\text { GSK3ßat Ser9 }\end{array}$ & Upregulation & $\mathrm{HCC}$ & {$[248]$} \\
\hline & $\begin{array}{l}\text { ipatasertib, } \\
\text { capivasertib, } \\
\text { uprosertib, and MK- } \\
2206\end{array}$ & inhibiting Akt & Downregulation & breast cancer & [249] \\
\hline & DS-8201a & targeting HER2 & Upregulation & breast cancer & {$[250]$} \\
\hline & Verteporfin & $\begin{array}{l}\text { inhibiting STAT1-IRF1- } \\
\text { TRIM28 signaling } \\
\text { cascade }\end{array}$ & Downregulation & $\begin{array}{l}\text { T-cell leukemia, B-cell leukemia, ovarian, osteoblastoma, and } \\
\text { NSCLC }\end{array}$ & [251] \\
\hline & LY294002 & inhibiting PI3K & Downregulation & gastric cancer & {$[61]$} \\
\hline & $\begin{array}{l}\text { cetuximab, erlotinib, } \\
\text { and selumetinib }\end{array}$ & $\begin{array}{l}\text { inhibiting MAPK } \\
\text { signaling }\end{array}$ & Downregulation & LUAD & [57] \\
\hline & trametinib & $\begin{array}{l}\text { inhibiting MAPK } \\
\text { signaling }\end{array}$ & Upregulation & breast cancer & {$[56]$} \\
\hline & Belinostat & inducing IFN- $\gamma$ & Upregulation & $\mathrm{HCC}$ & [252] \\
\hline & $\mathrm{C} 108$ & Inhibiting G3BP2 & Downregulation & GBM & [139] \\
\hline & Pembrolizumab & $\begin{array}{l}\text { inhibiting interaction of } \\
\text { PD-L1 with PD-1 }\end{array}$ & & urothelial cancer, melanoma, HNSCC, and NSCLC & [253] \\
\hline & $\begin{array}{l}\text { Nivolumab and } \\
\text { Atezolizumab }\end{array}$ & $\begin{array}{l}\text { inhibiting interaction of } \\
\text { PD-L1 with PD-1 }\end{array}$ & & NSCLC, urothelial cancer, RCC, and melanoma & [253] \\
\hline & $\begin{array}{l}\text { Durvalumab and } \\
\text { Avelumab }\end{array}$ & $\begin{array}{l}\text { inhibiting interaction of } \\
\text { PD-L1 with PD-1 }\end{array}$ & & urothelial cancer & [253] \\
\hline & Envafolimab & $\begin{array}{l}\text { inhibiting interaction of } \\
\text { PD-L1 with PD-1 }\end{array}$ & & $\begin{array}{l}\text { prostate cancer, NSCLC, breast cancer, gastrointestinal } \\
\text { cancer, melanoma, cervical cancer, HNSCC, bladder cancer, } \\
\text { cholangiocarcinoma }\end{array}$ & [254] \\
\hline & $\begin{array}{l}\text { MDX-1105 and CS- } \\
1001\end{array}$ & $\begin{array}{l}\text { inhibiting interaction of } \\
\text { PD-L1 with PD-1 }\end{array}$ & & NSCLC, melanoma, RCC & [9] \\
\hline & CK-301 & $\begin{array}{l}\text { inhibiting interaction of } \\
\text { PD-L1 with PD-1 }\end{array}$ & & $\begin{array}{l}\text { NSCLC, HNSCC, melanoma, RCC, urothelial cancer, Hodgkin's } \\
\text { lymphoma }\end{array}$ & [254] \\
\hline & TQB-2450 & $\begin{array}{l}\text { inhibiting interaction of } \\
\text { PD-L1 with PD-1 }\end{array}$ & & melanoma & [254] \\
\hline & BGB-A333 & $\begin{array}{l}\text { inhibiting interaction of } \\
\text { PD-L1 with PD-1 }\end{array}$ & & advanced solid tumor & [254] \\
\hline \multirow[t]{3}{*}{$\begin{array}{l}\text { CTLA- } \\
4\end{array}$} & Ipilimumab & $\begin{array}{l}\text { inhibiting interaction of } \\
\text { CTLA-4 with B7 }\end{array}$ & & $\begin{array}{l}\text { RCC, prostate cancer, cervical cancer, CRC, NSCLC, gastric } \\
\text { cancer, pancreatic cancer, ovarian cancer, urothelial cancer, } \\
\text { and melanoma }\end{array}$ & [255] \\
\hline & Tremelimumab & $\begin{array}{l}\text { inhibiting interaction of } \\
\text { CTLA-4 with B7 }\end{array}$ & & $\mathrm{HCC}$ & [256] \\
\hline & p344 & $\begin{array}{l}\text { inhibiting interaction of } \\
\text { CTLA-4 with B7 }\end{array}$ & & & {$[257]$} \\
\hline
\end{tabular}


Table 3 Potential drugs intervening PD-L1 and CTLA-4 (Continued)

\begin{tabular}{clll}
\hline Drugs & Mechanism & $\begin{array}{l}\text { PD-L1 or } \\
\text { CTLA-4 }\end{array}$ & Cancer types \\
\hline SAHA & Downregulation & References \\
CKD-L & Upregulation & {$[258]$} & 259] \\
\hline
\end{tabular}

immunosuppression in breast cancer [245]. Temozolomide (TMZ)-treated GBM was observed with upregulated PD-L1 expression [246]. Further, after the TMZ challenge, actinomycin D suppressed PD-L1 expression in GBM [246]. Pemetrexed and sildenafil suppressed PD-L1 expression in NSCLC, where the inhibitory effect was enhanced by histone deacetylase inhibitors AR42 and sodium valproate [247]. Notably, AR42 and valproate alone downregulated PD-L1 expression [247]. Disulfiram combined with Copper (DSF/Cu ${ }^{2+}$ ) upregulated PD-L1 expression by inactivating PARP1 and phosphorylating GSK3ßat Ser9 in HCC [248]. DSF/Cu ${ }^{2+}$ also inhibited $\mathrm{T}$ cell infiltration while failed to hamper $\mathrm{HCC}$ tumor growth [248]. The Akt inhibitors ipatasertib, capivasertib, uprosertib, and MK-2206 inhibit PD-L1 expression in breast cancer [249]. Trastuzumab deruxtecan (DS-8201a), a HER2-targeting drug, enhanced PD-L1 expression and $\mathrm{CD} 8+\mathrm{T}$ cell infiltration in breast cancer, which DS-8201a also had synergistic effect with anti-PD1 therapy [250]. Verteporfin has been explored as a potential inhibitor that hampers IFN- $\gamma$-derived PD-L1 expression by disrupting the STAT1-IRF1-TRIM28 signaling cascade T-cell leukemia, B-cell leukemia, ovarian, osteoblastoma, and NSCLC [251]. PI3K inhibitor (LY294002) downregulated PD-L1 expression in gastric cancer [61]. EGFR inhibitors (cetuximab and erlotinib) or MEK inhibitor (selumetinib) suppressed MAPK signaling-mediated EGF-induced and IFN- $\gamma$-induced PD-L1 expression in LUAD [57]. In contrast, MEK inhibitor (trametinib), suppressing MAPK signaling, enhanced the IFN- $\gamma$-stimulated PD-L1 expression in breast cancer [56]. Besides, the insignificant alterations and IFN- $\gamma$-stimulated PD-L1 expression in diverse cancer cell lines after MAPK inhibitor treatment shed light on the individual regulatory role of PD-L1 in various cancer types [62, 260]. Belinostat enhanced IFN- $\gamma$ production and upregulated PD-L1 expression in HCC, which Belinostat also had a synergistic effect of anti-PD-1 therapy [252]. C108 repressed G3BP2 and downregulated PD-L1 expression in breast cancer and GBM [139].

Among the multiple drugs developed for inhibiting the interaction of PD-L1 with PD-1, Pembrolizumab, Nivolumab, Atezolizumab, Durvalumab, and Avelumab have been approved by FDA. Pembrolizumab showed efficiency in regulating the interaction of PD-L1 with PD-1 in urothelial cancer, melanoma, HNSCC, and NSCLC [253]. Similarly, Nivolumab and Atezolizumab inhibited
PD-L1 in NSCLC, urothelial cancer, RCC, and melanoma [253]. Durvalumab and Avelumab inhibited PD-L1 in urothelial cancer [253]. Other PD-L1 inhibitors have also been investigated in many clinical trials. Envafolimab (KN 035 or ASC 22) inhibited the interaction of PD-L1 with PD-1 and exhibited encouraging anti-tumor activity in a phase I clinical trial of advanced solid tumor [254]. Besides, the clinical efficacy and safety of BMS936559 (MDX-1105) and CS-1001 were explored in a phase I clinical trial of advanced solid tumor [9]. Several drugs are currently undergoing clinical trials. CK-301 showed high binding affinity for PD-L1 and increased IFN- $\gamma$ in a preclinical research [254]. CBT-502 (TQB2450 ) is another inhibitor of PD-L1 with increased IFN$\gamma$ in melanoma [254]. Except for inhibiting PD-L1, BGBA333 inhibited T cell apoptosis and increased T cell proliferation [254].

As for CTLA-4, Ipilimumab, a drug approved by FDA, docked to the MYPPPY motif of CTLA-4 and showed efficacy in inhibiting CTLA-4 in RCC, prostate cancer, cervical cancer, CRC, NSCLC, gastric cancer, pancreatic cancer, ovarian cancer, urothelial cancer, and melanoma [255]. Tremelimumab inhibited CTLA-4 in phase II clinical trials of HCC [256]. A synthetic peptide (p344) was demonstrated to bind to the MYPPPY motif of CTLA-4 and blocked its interaction with B7 ligands [257]. As a HDAC inhibitor (HDACi), suberoylanilide hydroxamic acid (SAHA) synergizes with tacrolimus (FK506) to increase Foxp3 and CTLA-4 expression [258]. Besides, HDAC6 inhibitor, CKD-L, increased CTLA-4 expression in Treg [259].

\section{Conclusion}

Immunotherapies represented by targeting PD-1/ PD-L1 and CTLA-4/B7 pathways have shown remarkable clinical efficacies against various cancer types. However, only a small proportion of patients exhibit favorable responses to anti-PD1-PD-L1 or anti-CTLA-4/B7 therapy. Overexpression of PD-L1 and CTLA-4 are recognized as a vital suppressor of anti-tumor immunity and associated with better therapy response and increased clinical benefit. Given the unprecedented predictive values of PD-L1 and CTLA-4 expression in immunotherapy, investigating the diverse regulators on PD-L1 and CTLA-4 expression that could potentially influence immunotherapy efficacy will contribute to the individualized clinical management of cancer patients. 
In this review, the mechanisms of PD-L1 regulation were categorized into genetic alteration, epigenetic regulation, inflammatory signaling, and oncogenic signaling at the levels of DNA, regulation at RNA, regulation at protein, extracellular secretion, indirect regulation by biomarkers, and potential drug intervention. In summary, IFN- $\gamma$ plays a pivotal role in inducing PD-L1 expression through epigenetic regulation, transcriptional regulation, posttranscriptional regulation, and extracellular secretion. In contrast, there is limited literature on the regulatory mechanisms of CTLA-4, with the available literature indicating that the regulation of CTLA-4 mainly depends on its localization within the cell. Targeting IFN- $\gamma$ and regulating its localization within the cell could perceivably promote the anti-tumor immunotherapy responses. Some potential drugs targeting the PD-L1 regulators, such as IFN- $\gamma$, MAPK, and GSK3 $\beta$ exhibited remarkable synergistic anti-tumor effect with ICIs. Notably, the regulation of PD-L1 and CTLA-4 expressions have some similarities in HDAC, methylation of DNA at CpG sites, IL-2, STAT1, c-MYC at DNA level, and miRNA regulation at RNA level. Developing drugs targeting the mutual regulators of CTLA-4 and PD-L1 is expected to improve the therapeutic efficacy.

Further studies should be conducted to investigate more valuable PD-L1 and CTLA-4 regulators to improve the efficacy of immunotherapy and facilitate individualized cancer treatment. Moreover, some regulators with potential synergistic effect with the current ICIs should be expected to be explored in clinical trials.

\footnotetext{
Abbreviations

CTLA-4: Cytotoxic T-lymphocyte-associated antigen 4; PD-1: Programmed death 1; PD-L1: Programmed cell death-ligand 1; ICl: Immune checkpoint inhibitor; CAR: Chimeric antigen receptor; CRC: Colorectal carcinoma; NSCL C: Non-small cell lung cancer; TILs: Tumor-infiltrating lymphocytes; TAMs: Tumor-associated macrophages; DCs: Dendritic cells; Tregs: Regulatory T cells; CAFs: Cancer-associated fibroblasts; SCLC: Small cell lung cancer; EBV: Epstein-barr virus; OSCC: Oral squamous cell carcinoma; HDACs: Histone deacetylases; HNSCC: Head and neck squamous cell carcinomas; DNMTis: DNA methyltransferase inhibitors; ERVs: Endogenous retroviruses; STING: Stimulator of IFN genes; EZH2: Enhancer of zeste 2 polycomb repressive complex 2 subunit; HCC: Hepatocellular carcinoma; NF-kB: Nuclear factor kappa-light-chain-enhancer of activated B cells; GCA: Gastric cardia adenocarcinoma; EMT: Epithelial to mesenchymal transition; TFH: T follicular helper; IFNGR: Interferon-gamma receptor; JAK-STAT: Janus kinase-signal transducer and activator of transcription; IRFs: Interferon-responsive factors; LPS: Lipopolysaccharide; TLR: Toll-like receptor; poly(l:C): Polyinosinicpolycytidylic acid; TNF-a: Tumor necrosis factor-a; TGF- $\beta$ : Transforming growth factor- $\beta$; RCC: Renal cell carcinoma; PTPRO: Protein tyrosine phosphatase receptor type O; GBM: Glioblastoma; EGFR: Epidermal growth factor receptor; ERK: Extracellular signal-regulated kinase; MAPK: Mitogenactivated protein kinase; TNBC: Triple negative breast cancer; BRAFi: BRAF inhibition; MEKi: MEK inhibition; ATM: Ataxia Telangiectasia Mutated; TME: Tumor microenvironment; ESCC: Esophageal squamous cell carcinoma; ALK: Anaplastic lymphoma kinase; HGF: Hepatocyte growth factor; BET: Bromodomain and extraterminal; DSB: DNA double-strand break; AP1: Activator protein-1; SHH: SONIC hedgehog; LMP1: Latent membrane protein-1; m6A: N6-methyladenosine; LUAD: Lung adenocarcinoma; FTO: Fat mass and obesity-associated protein; AML: Acute myeloid leukemia; UTR: Untranslated regions; G3BP2: GTPase-activating protein (SH3 domain)binding protein 2; NFAT: Nuclear factor of activated T-cells; Foxp3: Forkhead
}

box P3; CLL: Chronic lymphocytic leukemia; Cbl: CASITAS B-lineage lymphoma; USP22: Ubiquitin-specific peptidase 22; UCHL1: Ubiquitin C-terminal hydrolase L1; CDK4: Cyclin D/cyclin-dependent kinase 4; CSN5: COP9 signalosome 5; AMPK: AMP-activated protein kinase; GSK3B: Glycogen synthase kinase 33; CSCs: Cancer stem-like cells; TMB: Tumor mutation burden; MSI: Microsatellite instability; AP-1: Plasma membrane-associated clathrin adaptor protein 1; TRIM: T cell receptor-interacting molecule;

PLD: Phospholipase D; ARF: ADP ribosylation factor

\section{Supplementary Information}

The online version contains supplementary material available at https://doi. org/10.1186/s13046-021-01987-7.

Additional file 1.

\section{Acknowledgements}

Not applicable.

\section{Authors' contributions}

$H Z, Q C$, and ZD drafted the manuscript and prepared the figures. WW, WZ, $L Z$, and ZW collected the related references and participated in discussion. $H Z, Q C$, and ZL designed this review and revised the manuscript. All authors contributed to this manuscript. All authors read and approved the final manuscript.

\section{Funding}

This work was supported by the National Natural Science Foundation of China (NO.82073893, 81873635, 81472693 and 81903663). China Postdoctoral Science Foundation (NO. 2018M633002), Hunan Provincial Natural Science Foundation of China (NO. 2018SK2101, 2018JJ3838), Hunan Provincial Health Committee Foundation of China (C2019186). Xiangya Hospital Central South University postdoctoral foundation.

\section{Availability of data and materials}

Not applicable.

\section{Declarations}

Ethics approval and consent to participate

Not applicable.

Consent for publication

Not applicable.

\section{Competing interests}

The authors declare that they have no competing interests.

\section{Author details}

'Department of Neurosurgery, Xiangya Hospital, Central South University, Changsha, China. ${ }^{2}$ Department of Oncology, Xiangya Hospital, Central South University, Changsha, China. ${ }^{3}$ One-third Lab, College of Bioinformatics Science and Technology, Harbin Medical University, Harbin, China. ${ }^{4}$ Department of Pharmacy, Xiangya Hospital, Central South University, Changsha, China. ${ }^{5}$ National Clinical Research Center for Geriatric Disorders, Xiangya Hospital, Central South University, Changsha, China.

Received: 11 March 2021 Accepted: 17 May 2021

Published online: 04 June 2021

\section{References}

1. Qin S, Xu L, Yi M, Yu S, Wu K, Luo S. Novel immune checkpoint targets: moving beyond PD-1 and CTLA-4. Mol Cancer. 2019;18(1):155.

2. Zhai L, Ladomersky $E$, Lenzen $A$, et al. IDO1 in cancer: a Gemini of immune checkpoints. Cell Mol Immunol. 2018;15(5):447-57.

3. Hodi FS, O'Day SJ, McDermott DF, et al. Improved survival with ipilimumab in patients with metastatic melanoma. N Engl J Med. 2010;363(8):711-23.

4. Sun C, Mezzadra R, Schumacher TN. Regulation and function of the PD-L1 checkpoint. Immunity. 2018;48(3):434-52. 
5. Kythreotou A, Siddique A, Mauri FA, Bower M, Pinato DJ. Pd-L1. J Clin Pathol. 2018;71(3):189-94.

6. Rowshanravan B, Halliday N, Sansom DM. CTLA-4: a moving target in immunotherapy. Blood. 2018;131(1):58-67.

7. Schachter J, Ribas A, Long GV, et al. Pembrolizumab versus ipilimumab for advanced melanoma: final overall survival results of a multicentre, randomised, open-label phase 3 study (KEYNOTE-006). Lancet. 2017; 390(10105):1853-62.

8. Khoja L, Day D, Wei-Wu Chen T, Siu LL, Hansen AR. Tumour- and classspecific patterns of immune-related adverse events of immune checkpoint inhibitors: a systematic review. Ann Oncol. 2017;28(10):2377-85.

9. Brahmer JR, Tykodi SS, Chow LQ, et al. Safety and activity of anti-PD-L1 antibody in patients with advanced cancer. N Engl J Med. 2012;366(26): 2455-65.

10. Gong J, Chehrazi-Raffle A, Reddi S, Salgia R. Development of PD-1 and PDL1 inhibitors as a form of cancer immunotherapy: a comprehensive review of registration trials and future considerations. J Immunother Cancer. 2018; 6(1):8.

11. Rotte A. Combination of CTLA-4 and PD-1 blockers for treatment of cancer. J Exp Clin Cancer Res. 2019;38(1):255.

12. Hellmann MD, Kim TW, Lee CB, et al. Phase Ib study of atezolizumab combined with cobimetinib in patients with solid tumors. Ann Oncol. 2019; 30(7):1134-42

13. Reardon DA, Brandes AA, Omuro A, et al. Effect of Nivolumab vs Bevacizumab in Patients With Recurrent Glioblastoma: The CheckMate 143 Phase 3 Randomized Clinical Trial. JAMA Oncol. 2020;6(7):1003-10.

14. Chae YK, Arya A, lams W, et al. Current landscape and future of dual antiCTLA4 and PD-1/PD-L1 blockade immunotherapy in cancer; lessons learned from clinical trials with melanoma and non-small cell lung cancer (NSCLC). J Immunother Cancer. 2018:6(1):39.

15. Egen JG, Kuhns MS, Allison JP. CTLA-4: new insights into its biological function and use in tumor immunotherapy. Nat Immunol. 2002;3(7):611-8.

16. Bardhan K, Anagnostou T, Boussiotis VA. The PD1:PD-L1/2 Pathway from Discovery to Clinical Implementation. Front Immunol. 2016;7:550.

17. Suriyo T, Fuangthong M, Artpradit C, et al. Inhibition of T-cell-mediated immune response via the PD-1/ PD-L1 axis in cholangiocarcinoma cells. Eur J Pharmacol. 2021:897:173960.

18. Goodman AM, Piccioni D, Kato S, et al. Prevalence of PDL1 Amplification and Preliminary Response to Immune Checkpoint Blockade in Solid Tumors. JAMA Oncol. 2018;4(9):1237-44.

19. Daassi D, Mahoney KM, Freeman GJ. The importance of exosomal PDL1 in tumour immune evasion. Nat Rev Immunol. 2020;20(4):209-15.

20. Wienand K, Chapuy B, Stewart C, et al. Genomic analyses of flow-sorted Hodgkin Reed-Sternberg cells reveal complementary mechanisms of immune evasion. Blood Adv. 2019;3(23):4065-80.

21. Roemer MG, Advani RH, Ligon AH, et al. PD-L1 and PD-L2 Genetic Alterations Define Classical Hodgkin Lymphoma and Predict Outcome. J Clin Oncol. 2016;34(23):2690-7.

22. George J, Saito M, Tsuta K, et al. Genomic Amplification of CD274 (PD-L1) in Small-Cell Lung Cancer. Clin Cancer Res. 2017;23(5):1220-6.

23. Ikeda S, Okamoto T, Okano S, et al. PD-L1 Is Upregulated by Simultaneous Amplification of the PD-L1 and JAK2 Genes in Non-Small Cell Lung Cancer. J Thorac Oncol. 2016;11(1):62-71.

24. Twa DD, Chan FC, Ben-Neriah S, et al. Genomic rearrangements involving programmed death ligands are recurrent in primary mediastinal large B-cell lymphoma. Blood. 2014;123(13):2062-5.

25. Cancer Genome Atlas Research N. Comprehensive molecular characterization of gastric adenocarcinoma. Nature. 2014;513(7517):202-9.

26. Straub M, Drecoll E, Pfarr N, et al. CD274/PD-L1 gene amplification and PDL1 protein expression are common events in squamous cell carcinoma of the oral cavity. Oncotarget. 2016;7(11):12024-34.

27. Wang H, Fu C, Du J, et al. Enhanced histone $\mathrm{H}_{3}$ acetylation of the PD-L1 promoter via the COP1/C-Jun/HDAC3 axis is required for PD-L1 expression in drug-resistant cancer cells. J Exp Clin Cancer Res. 2020;39(1):29.

28. $M L, P P V, T K$, et al. Essential role of HDAC6 in the regulation of PD-L1 in melanoma. Mol Oncol. 2016;10(5):735-50.

29. Goltz D, Gevensleben H, Dietrich J, Dietrich D. PD-L1 (CD274) promoter methylation predicts survival in colorectal cancer patients. Oncoimmunology. 2017;6(1):e1257454.

30. Franzen A, Vogt TJ, Muller T, et al. PD-L1 (CD274) and PD-L2 (PDCD1LG2) promoter methylation is associated with HPV infection and transcriptional repression in head and neck squamous cell carcinomas. Oncotarget. 2018; 9(1):641-50.

31. Micevic G, Thakral D, McGeary M, Bosenberg MW. PD-L1 methylation regulates PD-L1 expression and is associated with melanoma survival. Pigment Cell Melanoma Res. 2019;32(3):435-40.

32. Marwitz S, Scheufele S, Perner S, Reck M, Ammerpohl O, Goldmann T. Epigenetic modifications of the immune-checkpoint genes CTLA4 and PDCD1 in non-small cell lung cancer results in increased expression. Clin Epigenetics. 2017;9:51

33. Lu C, Paschall AV, Shi H, et al. The MLL1-H3K4me3 axis-mediated PD-L1 expression and pancreatic cancer immune evasion. J Natl Cancer Inst. 2017; 109(6):djw283.

34. Darvin P, Sasidharan Nair V, Elkord E. PD-L1 Expression in Human Breast Cancer Stem Cells Is Epigenetically Regulated through Posttranslational Histone Modifications. J Oncol. 2019:2019:3958908.

35. Xiao G, Jin LL, Liu CQ, et al. EZH2 negatively regulates PD-L1 expression in hepatocellular carcinoma. J Immunother Cancer. 2019:7(1):300.

36. Noguchi T, Ward JP, Gubin MM, et al. Temporally Distinct PD-L1 Expression by Tumor and Host Cells Contributes to Immune Escape. Cancer Immunol Res. 2017;5(2):106-17.

37. Shao L, Hou W, Scharping NE, et al. IRF1 Inhibits Antitumor Immunity through the Upregulation of PD-L1 in the Tumor Cell. Cancer Immunol Res. 2019;7(8):1258-66.

38. Chang LC, Chen TP, Kuo WK, Hua CC. The Protein Expression of PDL1 Is Highly Correlated with Those of elF2alpha and ATF4 in Lung Cancer. Dis Markers. 2018;2018:5068701.

39. Garcia-Diaz A, Shin DS, Moreno BH, et al. Interferon Receptor Signaling Pathways Regulating PD-L1 and PD-L2 Expression. Cell Rep. 2019;29(11): 3766.

40. Lu YC, Yeh WC, Ohashi PS. LPS/TLR4 signal transduction pathway. Cytokine. 2008;42(2):145-51

41. Qian Y, Deng J, Geng L, et al. TLR4 signaling induces B7-H1 expression through MAPK pathways in bladder cancer cells. Cancer Invest. 2008;26(8): 816-21.

42. Boes M, Meyer-Wentrup F. TLR3 triggering regulates PD-L1 (CD274) expression in human neuroblastoma cells. Cancer Lett. 2015:361(1):49-56.

43. Wang $X$, Yang L, Huang F, et al. Inflammatory cytokines IL-17 and TNF-alpha up-regulate PD-L1 expression in human prostate and colon cancer cells. Immunol Lett. 2017;184:7-14.

44. Quandt D, Jasinski-Bergner S, Muller U, Schulze B, Seliger B. Synergistic effects of IL-4 and TNFalpha on the induction of B7-H1 in renal cell carcinoma cells inhibiting allogeneic T cell proliferation. J Transl Med. 2014; 12:151.

45. Carbotti G, Barisione G, Airoldi I, et al. IL-27 induces the expression of IDO and PD-L1 in human cancer cells. Oncotarget. 2015;6(41):43267-80.

46. Xu L, Chen $X$, Shen $M$, et al. Inhibition of IL-6-JAK/Stat3 signaling in castration-resistant prostate cancer cells enhances the NK cell-mediated cytotoxicity via alteration of PD-L1/NKG2D ligand levels. Mol Oncol. 2018; 12(3):269-86.

47. Zhang W, Liu Y, Yan Z, et al. IL-6 promotes PD-L1 expression in monocytes and macrophages by decreasing protein tyrosine phosphatase receptor type $\mathrm{O}$ expression in human hepatocellular carcinoma. J Immunother Cancer. 2020:8(1):e000285.

48. Lamano JB, Lamano JB, Li YD, et al. Glioblastoma-Derived IL6 Induces Immunosuppressive Peripheral Myeloid Cell PD-L1 and Promotes Tumor Growth. Clin Cancer Res. 2019;25(12):3643-57.

49. Shen MJ, Xu LJ, Yang $L$, et al. Radiation alters PD-L1/NKG2D ligand levels in lung cancer cells and leads to immune escape from NK cell cytotoxicity via IL-6-MEK/Erk signaling pathway. Oncotarget. 2017;8(46) 80506-20.

50. Jiang C, Yuan F, Wang J, Wu L. Oral squamous cell carcinoma suppressed antitumor immunity through induction of PD-L1 expression on tumorassociated macrophages. Immunobiology. 2017;222(4):651-7.

51. Ni XY, Sui HX, Liu Y, Ke SZ, Wang YN, Gao FG. TGF-beta of lung cancer microenvironment upregulates B7H1 and GITRL expression in dendritic cells and is associated with regulatory T cell generation. Oncol Rep. 2012;28(2): 615-21.

52. David JM, Dominguez C, McCampbell KK, Gulley JL, Schlom J, Palena C. A novel bifunctional anti-PD-L1/TGF-beta Trap fusion protein (M7824) efficiently reverts mesenchymalization of human lung cancer cells. Oncoimmunology. 2017;6(10):e1349589. 
53. Akbay EA, Koyama S, Carretero J, et al. Activation of the PD-1 pathway contributes to immune escape in EGFR-driven lung tumors. Cancer Discov. 2013;3(12):1355-63.

54. Gainor JF, Shaw AT, Sequist LV, et al. EGFR Mutations and ALK Rearrangements Are Associated with Low Response Rates to PD-1 Pathway Blockade in Non-Small Cell Lung Cancer: A Retrospective Analysis. Clin Cancer Res. 2016;22(18):4585-93.

55. Liu J, Hamrouni A, Wolowiec D, et al. Plasma cells from multiple myeloma patients express B7-H1 (PD-L1) and increase expression after stimulation with IFN-\{gamma\} and TLR ligands via a MyD88-, TRAF6-, and MEKdependent pathway. Blood. 2007;110(1):296-304

56. Loi S, Dushyanthen S, Beavis PA, et al. RAS/MAPK activation is associated with reduced tumor-infiltrating lymphocytes in triplenegative breast cancer: therapeutic cooperation between MEK and PD1/PD-L1 immune checkpoint inhibitors. Clin Cancer Res. 2016;22(6): 1499-509.

57. Stutvoet TS, Kol A, de Vries EG, et al. MAPK pathway activity plays a key role in PD-L1 expression of lung adenocarcinoma cells. J Pathol. 2019;249(1):52-64

58. Jiang X, Zhou J, Giobbie-Hurder A, Wargo J, Hodi FS. The activation of MAPK in melanoma cells resistant to BRAF inhibition promotes PD-L1 expression that is reversible by MEK and PI3K inhibition. Clin Cancer Res. 2013;19(3):598-609.

59. Sumimoto H, Takano A, Teramoto K, Daigo Y. RAS-Mitogen-Activated Protein Kinase Signal Is Required for Enhanced PD-L1 Expression in Human Lung Cancers. PLoS One. 2016;11(11):e0166626.

60. Zhang $Y$, Velez-Delgado A, Mathew E, et al. Myeloid cells are required for PD-1/PD-L1 checkpoint activation and the establishment of an immunosuppressive environment in pancreatic cancer. Gut. 2017:66(1): 124-36.

61. Kim YB, Ahn JM, Bae WJ, Sung CO, Lee D. Functional loss of ARID1A is tightly associated with high PD-L1 expression in gastric cancer. Int J Cancer. 2019;145(4):916-26.

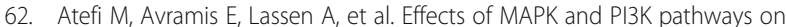
PD-L1 expression in melanoma. Clin Cancer Res. 2014;20(13):3446-57.

63. Lastwika KJ, Wilson W 3rd, Li QK, et al. Control of PD-L1 Expression by Oncogenic Activation of the AKT-mTOR Pathway in Non-Small Cell Lung Cancer. Cancer Res. 2016;76(2):227-38.

64. Parsa AT, Waldron JS, Panner A, et al. Loss of tumor suppressor PTEN function increases B7-H1 expression and immunoresistance in glioma. Nat Med. 2007;13(1):84-8.

65. Song M, Chen D, Lu B, et al. PTEN loss increases PD-L1 protein expression and affects the correlation between PD-L1 expression and clinical parameters in colorectal cancer. PLoS One. 2013;8(6):e65821.

66. Xu C, Fillmore CM, Koyama S, et al. Loss of Lkb1 and Pten leads to lung squamous cell carcinoma with elevated PD-L1 expression. Cancer Cell. 2014; 25(5):590-604

67. Fiedler M, Schulz D, Piendl G, et al. Buparlisib modulates PD-L1 expression in head and neck squamous cell carcinoma cell lines. Exp Cell Res. 2020; 396(1):112259

68. Suh $\mathrm{KJ}$, Sung JH, Kim JW, et al. EGFR or HER2 inhibition modulates the tumor microenvironment by suppression of PD-L1 and cytokines release. Oncotarget. 2017;8(38):63901-10.

69. Huang TY, Chang TC, Chin YT, et al. NDAT Targets PI3K-Mediated PD-L1 upregulation to reduce proliferation in gefitinib-resistant colorectal cancer. Cells. 2020;9(8):1830

70. Mittendorf EA, Philips AV, Meric-Bernstam F, et al. PD-L1 expression in triplenegative breast cancer. Cancer Immunol Res. 2014;2(4):361-70.

71. Chen M, Pockaj B, Andreozzi M, et al. JAK2 and PD-L1 Amplification Enhance the Dynamic Expression of PD-L1 in Triple-negative Breast Cancer. Clin Breast Cancer. 2018;18(5):e1205-15

72. Shen $M, X u Z, X u W$, et al. Inhibition of ATM reverses EMT and decreases metastatic potential of cisplatin-resistant lung cancer cells through JAK STAT3/PD-L1 pathway. J Exp Clin Cancer Res. 2019:38(1):149.

73. Gowrishankar K, Gunatilake D, Gallagher SJ, Tiffen J, Rizos H, Hersey P. Inducible but not constitutive expression of PD-L1 in human melanoma cells is dependent on activation of NF-kappaB. PLoS One. 2015;10(4): e0123410

74. Bouillez A, Rajabi H, Jin C, et al. MUC1-C integrates PD-L1 induction with repression of immune effectors in non-small-cell lung cancer. Oncogene. 2017;36(28):4037-46.
75. Cai H, Yan L, Liu N, Xu M, Cai H. IFl16 promotes cervical cancer progression by upregulating PD-L1 in immunomicroenvironment through STING-TBK1NF-kB pathway. Biomed Pharmacother. 2020;123:109790.

76. Noman MZ, Janji B, Abdou A, et al. The immune checkpoint ligand PD-L1 is upregulated in EMT-activated human breast cancer cells by a mechanism involving ZEB-1 and miR-200. Oncoimmunology. 2017;6(1):e1263412.

77. Roux C, Jafari SM, Shinde R, et al. Reactive oxygen species modulate macrophage immunosuppressive phenotype through the up-regulation of PD-L1. Proc Natl Acad Sci U S A. 2019;116(10):4326-35.

78. Barsoum IB, Smallwood CA, Siemens DR, Graham CH. A mechanism of hypoxia-mediated escape from adaptive immunity in cancer cells. Cancer Res. 2014;74(3):665-74.

79. Koh J, Jang JY, Keam B, et al. EML4-ALK enhances programmed cell deathligand 1 expression in pulmonary adenocarcinoma via hypoxia-inducible factor (HIF)-1alpha and STAT3. Oncoimmunology. 2016;5(3):e1108514.

80. Noman MZ, Desantis G, Janji B, et al. PD-L1 is a novel direct target of HIF1alpha, and its blockade under hypoxia enhanced MDSC-mediated T cell activation. J Exp Med. 2014;211(5):781-90.

81. Walmsley SR, Print C, Farahi N, et al. Hypoxia-induced neutrophil survival is mediated by HIF-1alpha-dependent NF-kappaB activity. J Exp Med. 2005; 201(1):105-15

82. Jiang $Y$, Zhu $Y$, Wang $X$, et al. Temporal regulation of HIF-1 and NF-kappaB in hypoxic hepatocarcinoma cells. Oncotarget. 2015;6(11):9409-19.

83. Zhao $Y$, Wang $X X, W u$ W, et al. EZH2 regulates PD-L1 expression via HIF1alpha in non-small cell lung cancer cells. Biochem Biophys Res Commun. 2019:517(2):201-9.

84. Messai Y, Gad S, Noman MZ, et al. Renal Cell Carcinoma Programmed Death-ligand 1, a New Direct Target of Hypoxia-inducible Factor-2 Alpha, is Regulated by von Hippel-Lindau Gene Mutation Status. Eur Urol. 2016;70(4): 623-32.

85. Atsaves V, Tsesmetzis N, Chioureas D, et al. PD-L1 is commonly expressed and transcriptionally regulated by STAT3 and MYC in ALK-negative anaplastic large-cell lymphoma. Leukemia. 2017;31(7):1633-7.

86. Casey SC, Tong L, Li Y, et al. MYC regulates the antitumor immune response through CD47 and PD-L1. Science. 2016;352(6282):227-31.

87. Liang MQ, Yu FQ, Chen C. C-Myc regulates PD-L1 expression in esophageal squamous cell carcinoma. Am J Transl Res. 2020;12(2):379-88.

88. Kim EY, Kim A, Kim SK, Chang YS. MYC expression correlates with PD-L1 expression in non-small cell lung cancer. Lung Cancer. 2017;110:63-7.

89. Wang J, Jia Y, Zhao S, et al. BIN1 reverses PD-L1-mediated immune escape by inactivating the c-MYC and EGFR/MAPK signaling pathways in non-small cell lung cancer. Oncogene. 2017;36(45):6235-43.

90. Pan $Y$, Fei $Q$, Xiong $P$, et al. Synergistic inhibition of pancreatic cancer with anti-PD-L1 and C-Myc inhibitor JQ1. Oncoimmunology. 2019;8(5):e1581529.

91. Wang J, Zhang R, Lin Z, et al. CDK7 inhibitor THZ1 enhances antiPD-1 therapy efficacy via the p38alpha/MYC/PD-L1 signaling in non-small cell lung cancer. J Hematol Oncol. 2020;13(1):99.

92. Cheng P, Eksioglu EA, Chen X, et al. S100A9-induced overexpression of PD1/PD-L1 contributes to ineffective hematopoiesis in myelodysplastic syndromes. Leukemia. 2019;33(8):2034-46.

93. Zou J, Zhuang M, Yu X, et al. MYC inhibition increases PD-L1 expression induced by IFN-gamma in hepatocellular carcinoma cells. Mol Immunol. 2018:101:203-9.

94. Marzec M, Zhang Q, Goradia A, et al. Oncogenic kinase NPM/ALK induces through STAT3 expression of immunosuppressive protein CD274 (PD-L1, B7H1). Proc Natl Acad Sci U S A. 2008;105(52):20852-7.

95. Yamamoto R, Nishikori M, Tashima M, et al. B7-H1 expression is regulated by MEKJERK signaling pathway in anaplastic large cell lymphoma and Hodgkin lymphoma. Cancer Sci. 2009;100(11):2093-100.

96. Ota K, Azuma K, Kawahara A, et al. Induction of PD-L1 Expression by the EML4-ALK Oncoprotein and Downstream Signaling Pathways in Non-Small Cell Lung Cancer. Clin Cancer Res. 2015;21(17):4014-21.

97. Shen J, Li S, Medeiros LJ, et al. PD-L1 expression is associated with ALK positivity and STAT3 activation, but not outcome in patients with systemic anaplastic large cell lymphoma. Mod Pathol. 2020;33(3):324-33.

98. Albitar M, Sudarsanam S, Ma W, et al. Correlation of MET gene amplification and TP53 mutation with PD-L1 expression in non-small cell lung cancer. Oncotarget. 2018;9(17):13682-93.

99. Peng S, Wang R, Zhang X, et al. EGFR-TKI resistance promotes immune escape in lung cancer via increased PD-L1 expression. Mol Cancer. 2019; 18(1):165. 
100. Ahn HK, Kim S, Kwon D, et al. MET receptor tyrosine kinase regulates the expression of co-stimulatory and co-inhibitory molecules in tumor cells and contributes to PD-L1-mediated suppression of immune cell function. Int J Mol Sci. 2019;20(17):4287.

101. Zhu H, Bengsch F, Svoronos N, et al. BET Bromodomain Inhibition Promotes Anti-tumor Immunity by Suppressing PD-L1 Expression. Cell Rep. 2016; 16(11):2829-37.

102. Hogg SJ, Vervoort SJ, Deswal S, et al. BET-bromodomain inhibitors engage the host immune system and regulate expression of the immune checkpoint ligand PD-L1. Cell Rep. 2017;18(9):2162-74.

103. Sato H, Niimi A, Yasuhara T, et al. DNA double-strand break repair pathway regulates PD-L1 expression in cancer cells. Nat Commun. 2017:8(1):1751.

104. Green MR, Rodig S, Juszczynski P, et al. Constitutive AP-1 activity and EBV infection induce PD-L1 in Hodgkin lymphomas and posttransplant lymphoproliferative disorders: implications for targeted therapy. Clin Cancer Res. 2012;18(6):1611-8

105. Chen BJ, Chapuy B, Ouyang J, et al. PD-L1 expression is characteristic of a subset of aggressive B-cell lymphomas and virus-associated malignancies. Clin Cancer Res. 2013;19(13):3462-73.

106. Holokai L, Chakrabarti J, Broda T, et al. Increased Programmed Death-Ligand 1 is an Early Epithelial Cell Response to Helicobacter pylori Infection. PLoS Pathog. 2019;15(1):e1007468.

107. Thiem A, Hesbacher S, Kneitz H, et al. IFN-gamma-induced PD-L1 expression in melanoma depends on p53 expression. J Exp Clin Cancer Res. 2019;38(1): 397.

108. Cortez MA, Ivan C, Valdecanas D, et al. PDL1 Regulation by p53 via miR-34. J Natl Cancer Inst. 2016;108(1):djv303.

109. Costa C, Indovina P, Mattioli E, et al. Correction: P53-regulated miR-320a targets PDL1 and is downregulated in malignant mesothelioma. Cell Death Dis. 2020;11(10):867.

110. Kim SS, Harford JB, Moghe M, Slaughter T, Doherty C, Chang EH. A tumortargeting nanomedicine carrying the p53 gene crosses the blood-brain barrier and enhances anti-PD-1 immunotherapy in mouse models of glioblastoma. Int J Cancer. 2019;145(9):2535-46.

111. Yi L, Wu G, Guo L, Zou X, Huang P. Comprehensive Analysis of the PD-L1 and Immune Infiltrates of m(6) A RNA Methylation Regulators in Head and Neck Squamous Cell Carcinoma. Mol Ther Nucleic Acids. 2020;21:299-314.

112. Li Y, Gu J, Xu F, et al. Molecular characterization, biological function, tumor microenvironment association and clinical significance of $\mathrm{m} 6 \mathrm{~A}$ regulators in lung adenocarcinoma. Brief Bioinform. 2020.

113. Han D, Liu J, Chen C, et al. Anti-tumour immunity controlled through mRNA m(6) A methylation and YTHDF1 in dendritic cells. Nature. 2019;566(7743): $270-4$.

114. Tsuruta N, Tsuchihashi K, Ohmura H, et al. RNA N6-methyladenosine demethylase FTO regulates PD-L1 expression in colon cancer cells. Biochem Biophys Res Commun. 2020;530(1):235-9.

115. Anastasiadou E, Stroopinsky D, Alimperti S, et al. Epstein-Barr virus-encoded EBNA2 alters immune checkpoint PD-L1 expression by downregulating miR34a in B-cell lymphomas. Leukemia. 2019;33(1):132-47.

116. Wang X, Li J, Dong K, et al. Tumor suppressor miR-34a targets PD-L1 and functions as a potential immunotherapeutic target in acute myeloid leukemia. Cell Signal. 2015;27(3):443-52.

117. Jia $L, X i$, Wang $H$, et al. miR-142-5p regulates tumor cell PD-L1 expression and enhances anti-tumor immunity. Biochem Biophys Res Commun. 2017; 488(2):425-31.

118. Cioffi M, Trabulo SM, Vallespinos M, et al. The miR-25-93-106b cluster regulates tumor metastasis and immune evasion via modulation of CXCL12 and PD-L1. Oncotarget. 2017;8(13):21609-25.

119. Zhao L, Yu H, Yi S, et al. The tumor suppressor miR-138-5p targets PD-L1 in colorectal cancer. Oncotarget. 2016;7(29):45370-84.

120. Miao S, Mao X, Zhao S, et al. miR-217 inhibits laryngeal cancer metastasis by repressing AEG-1 and PD-L1 expression. Oncotarget. 2017;8(37):62143-53.

121. Chen L, Gibbons DL, Goswami S, et al. Metastasis is regulated via microRNA200/ZEB1 axis control of tumour cell PD-L1 expression and intratumoral immunosuppression. Nat Commun. 2014,5:5241

122. Xie G, Li W, Li R, et al. Helicobacter pylori promote B7-H1 expression by suppressing miR-152 and miR-200b in gastric cancer cells. PLoS One. 2017; 12(1):e0168822.

123. Wang W, Li F, Mao Y, et al. A miR-570 binding site polymorphism in the B7$\mathrm{H} 1$ gene is associated with the risk of gastric adenocarcinoma. Hum Genet. 2013;132(6):641-8
124. Audrito V, Serra S, Stingi A, et al. PD-L1 up-regulation in melanoma increases disease aggressiveness and is mediated through miR-17-5p. Oncotarget. 2017;8(9):15894-911.

125. Kao SC, Cheng YY, Williams M, et al. Tumor Suppressor microRNAs Contribute to the Regulation of PD-L1 Expression in Malignant Pleural Mesothelioma. J Thorac Oncol. 2017;12(9):1421-33.

126. Ashizawa M, Okayama H, Ishigame T, et al. miRNA-148a-3p Regulates Immunosuppression in DNA Mismatch Repair-Deficient Colorectal Cancer by Targeting PD-L1. Mol Cancer Res. 2019;17(6):1403-13.

127. Gao L, Guo Q, Li X, et al. MiR-873/PD-L1 axis regulates the stemness of breast cancer cells. EBioMedicine. 2019;41:395-407.

128. Xu S, Tao Z, Hai B, et al. miR-424(322) reverses chemoresistance via T-cell immune response activation by blocking the PD-L1 immune checkpoint. Nat Commun. 2016;7:11406.

129. Sun JR, Zhang X, Zhang Y. MiR-214 prevents the progression of diffuse large B-cell lymphoma by targeting PD-L1. Cell Mol Biol Lett. 2019;24:68.

130. Qu F, Ye J, Pan X, et al. MicroRNA-497-5p down-regulation increases PD-L1 expression in clear cell renal cell carcinoma. J Drug Target. 2019;27(1):67-74.

131. Xie WB, Liang LH, Wu KG, et al. MiR-140 Expression Regulates Cell Proliferation and Targets PD-L1 in NSCLC. Cell Physiol Biochem. 2018;46(2): 654-63.

132. Zhu J, Chen L, Zou L, et al. MiR-20b, -21, and -130b inhibit PTEN expression resulting in $\mathrm{B} 7-\mathrm{H} 1$ over-expression in advanced colorectal cancer. Hum Immunol. 2014;75(4):348-53.

133. Liu J, Fan L, Yu H, et al. Endoplasmic Reticulum Stress Causes Liver Cancer Cells to Release Exosomal miR-23a-3p and Up-regulate Programmed Death Ligand 1 Expression in Macrophages. Hepatology. 2019;70(1):241-58.

134. Dong P, Xiong Y, Yu J, et al. Control of PD-L1 expression by miR-140/142/ $340 / 383$ and oncogenic activation of the OCT4-miR-18a pathway in cervical cancer. Oncogene. 2018;37(39):5257-68.

135. Fujita Y, Yagishita S, Hagiwara K, et al. The clinical relevance of the miR-197/ CKS1B/STAT3-mediated PD-L1 network in chemoresistant non-small-cell lung cancer. Mol Ther. 2015;23(4):717-27.

136. Sheng Q, Zhang Y, Wang Z, Ding J, Song Y, Zhao W. Cisplatin-mediated down-regulation of miR-145 contributes to up-regulation of PD-L1 via the c-Myc transcription factor in cisplatin-resistant ovarian carcinoma cells. Clin Exp Immunol. 2020;200(1):45-52.

137. Coelho MA, de Carne TS, Rana S, et al. Oncogenic RAS Signaling Promotes Tumor Immunoresistance by Stabilizing PD-L1 mRNA. Immunity. 2017;47(6): 1083-99 e1086.

138. Yang K, Zhou J, Chen Y, et al. Angiotensin II contributes to intratumoral immunosuppressionvia induction of PD-L1 expression in non-small cell lung carcinoma. Int Immunopharmacol. 2020;84:106507.

139. Zhang $Y$, Yue C, Krichevsky AM, Garkavtsev I. Repression of the stress granule protein G3BP2 inhibits immune checkpoint molecule PD-L1. Mol Oncol. 2021.

140. Wang S, Xu L, Che $X$, et al. E3 ubiquitin ligases Cbl-b and c-Cbl downregulate PD-L1 in EGFR wild-type non-small cell lung cancer. FEBS Lett. 2018;592(4):621-30.

141. Huang X, Zhang Q, Lou Y, et al. USP22 Deubiquitinates CD274 to Suppress Anticancer Immunity. Cancer Immunol Res. 2019;7(10):1580-90.

142. Jingjing W, Wenzheng G, Donghua W, Guangyu H, Aiping Z, Wenjuan W. Deubiquitination and stabilization of programmed cell death ligand 1 by ubiquitin-specific peptidase 9, X-linked in oral squamous cell carcinoma. Cancer Med. 2018;7(8):4004-11.

143. Mao R, Tan X, Xiao Y, et al. Ubiquitin C-terminal hydrolase L1 promotes expression of programmed cell death-ligand 1 in non-small-cell lung cancer cells. Cancer Sci. 2020;111(9):3174-83.

144. Burr ML, Sparbier CE, Chan YC, et al. CMTM6 maintains the expression of PD-L1 and regulates anti-tumour immunity. Nature. 2017;549(7670): $101-5$.

145. Mezzadra R, Sun C, Jae LT, et al. Identification of CMTM6 and CMTM4 as PDL1 protein regulators. Nature. 2017;549(7670):106-10.

146. Zhang J, Bu X, Wang H, et al. Cyclin D-CDK4 kinase destabilizes PD-L1 via cullin 3-SPOP to control cancer immune surveillance. Nature. 2018; 553(7686):91-5.

147. Lim SO, Li CW, Xia W, et al. Deubiquitination and Stabilization of PD-L1 by CSN5. Cancer Cell. 2016:30(6):925-39.

148. Chan LC, Li CW, Xia W, et al. IL-6/JAK1 pathway drives PD-L1 Y112 phosphorylation to promote cancer immune evasion. J Clin Invest. 2019; 129(8):3324-38 
149. Cha JH, Yang WH, Xia W, et al. Metformin Promotes Antitumor Immunity via Endoplasmic-Reticulum-Associated Degradation of PD-L1. Mol Cell. 2018; 71(4):606-20 e607.

150. Li CW, Lim SO, Xia W, et al. Glycosylation and stabilization of programmed death ligand-1 suppresses T-cell activity. Nat Commun. 2016;7:12632.

151. Li H, Li CW, Li X, et al. MET Inhibitors Promote Liver Tumor Evasion of the Immune Response by Stabilizing PDL1. Gastroenterology. 2019;156(6):184961 e1813.

152. Hsu JM, Xia W, Hsu YH, et al. STT3-dependent PD-L1 accumulation on cancer stem cells promotes immune evasion. Nat Commun. 2018;9(1):1908.

153. D'Arrigo P, Russo M, Rea A, et al. A regulatory role for the co-chaperone FKBP51s in PD-L1 expression in glioma. Oncotarget. 2017;8(40):68291-304

154. Yang Y, Hsu JM, Sun L, et al. Palmitoylation stabilizes PD-L1 to promote breast tumor growth. Cell Res. 2019;29(1):83-6.

155. Yao H, Lan J, Li C, et al. Inhibiting PD-L1 palmitoylation enhances T-cell immune responses against tumours. Nat Biomed Eng. 2019;3(4):306-17.

156. Theodoraki MN, Yerneni SS, Hoffmann TK, Gooding WE, Whiteside TL. Clinical Significance of PD-L1(+) Exosomes in Plasma of Head and Neck Cancer Patients. Clin Cancer Res. 2018;24(4):896-905.

157. Poggio M, Hu T, Pai CC, et al. Suppression of Exosomal PD-L1 Induces Systemic Anti-tumor Immunity and Memory. Cell. 2019;177(2):414-27 e413.

158. Yang Y, Li CW, Chan LC, et al. Exosomal PD-L1 harbors active defense function to suppress $T$ cell killing of breast cancer cells and promote tumor growth. Cell Res. 2018;28(8):862-4.

159. Chen G, Huang AC, Zhang W, et al. Exosomal PD-L1 contributes to immunosuppression and is associated with anti-PD-1 response. Nature. 2018;560(7718):382-6.

160. Okuma Y, Hosomi Y, Nakahara Y, Watanabe K, Sagawa Y, Homma S. High plasma levels of soluble programmed cell death ligand 1 are prognostic for reduced survival in advanced lung cancer. Lung Cancer. 2017;104:1-6.

161. Okuma Y, Wakui H, Utsumi H, et al. Soluble Programmed Cell Death Ligand 1 as a Novel Biomarker for Nivolumab Therapy for Non-Small-cell Lung Cancer. Clin Lung Cancer. 2018;19(5):410-7 e411.

162. Zhou J, Mahoney KM, Giobbie-Hurder A, et al. Soluble PD-L1 as a Biomarker in Malignant Melanoma Treated with Checkpoint Blockade. Cancer Immunol Res. 2017;5(6):480-92.

163. Gong B, Kiyotani K, Sakata S, et al. Secreted PD-L1 variants mediate resistance to PD-L1 blockade therapy in non-small cell lung cancer. J Exp Med. 2019;216(4):982-1000

164. Chan TA, Yarchoan M, Jaffee $\mathrm{E}$, et al. Development of tumor mutation burden as an immunotherapy biomarker: utility for the oncology clinic. Ann Oncol. 2019;30(1):44-56.

165. Luchini C, Bibeau F, Ligtenberg MJL, et al. ESMO recommendations on microsatellite instability testing for immunotherapy in cancer, and its relationship with PD-1/PD-L1 expression and tumour mutational burden: a systematic review-based approach. Ann Oncol. 2019;30(8):1232-43.

166. Xing X, Guo J, Ding G, et al. Analysis of PD1, PDL1, PDL2 expression and T cells infiltration in 1014 gastric cancer patients. Oncoimmunology. 2018;7(3): e1356144.

167. Haragan A, Field JK, Davies MPA, Escriu C, Gruver A, Gosney JR. Heterogeneity of PD-L1 expression in non-small cell lung cancer: Implications for specimen sampling in predicting treatment response. Lung Cancer. 2019;134:79-84.

168. Sun Y, Sun Y, Yue S, Wang Y, Lu F. Histone Deacetylase Inhibitors in Cancer Therapy. Curr Top Med Chem. 2018;18(28):2420-8.

169. Booth L, Roberts JL, Poklepovic A, Kirkwood J, Dent P. HDAC inhibitors enhance the immunotherapy response of melanoma cells. Oncotarget. 2017;8(47):83155-70.

170. Roberts JL, Poklepovic A, Booth L, Dent P. The multi-kinase inhibitor lenvatinib interacts with the HDAC inhibitor entinostat to kill liver cancer cells. Cell Signal. 2020;70:109573.

171. Hegedus L, Rittler D, Garay T, et al. HDAC Inhibition Induces PD-L1 Expression in a Novel Anaplastic Thyroid Cancer Cell Line. Pathol Oncol Res. 2020:26(4):2523-35.

172. Booth L, Roberts $J$, Poklepovic A, et al. HDAC inhibitors enhance neratinib activity and when combined enhance the actions of an antiPD-1 immunomodulatory antibody in vivo. Oncotarget. 2017:8(52): 90262-77.

173. Terranova-Barberio M, Thomas S, Ali N, et al. HDAC inhibition potentiates immunotherapy in triple negative breast cancer. Oncotarget. 2017:8(69): 114156-72
174. Emran AA, Chatterjee A, Rodger EJ, et al. Targeting DNA Methylation and EZH2 Activity to Overcome Melanoma Resistance to Immunotherapy. Trends Immunol. 2019;40(4):328-44.

175. Dear AE. Epigenetic Modulators and the New Immunotherapies. N Engl J Med. 2016;374(7):684-6.

176. Li H, Chiappinelli KB, Guzzetta AA, et al. Immune regulation by low doses of the DNA methyltransferase inhibitor 5-azacitidine in common human epithelial cancers. Oncotarget. 2014;5(3):587-98.

177. Asgarova A, Asgarov K, Godet Y, et al. PD-L1 expression is regulated by both DNA methylation and NF-kB during EMT signaling in non-small cell lung carcinoma. Oncoimmunology. 2018;7(5):e1423170.

178. Zhu T, Hu Z, Wang Z, et al. Epigenetically silenced PD-L1 confers drug resistance to anti-PD1 therapy in gastric cardia adenocarcinoma. Int Immunopharmacol. 2020;82:106245.

179. Howe FS, Fischl H, Murray SC, Mellor J. Is H3K4me3 instructive for transcription activation? Bioessays. 2017;39(1):1-12

180. Peng D, Kryczek I, Nagarsheth $\mathrm{N}$, et al. Epigenetic silencing of TH1-type chemokines shapes tumour immunity and immunotherapy. Nature. 2015; 527(7577):249-53

181. Li F, Zhao X, Zhang Y, et al. TFH cells depend on Tcf1-intrinsic HDAC activity to suppress CTLA4 and guard B-cell help function. Proc Natl Acad Sci U S A. 2021;118(2):e2014562118.

182. de Vos L, Grunwald I, Bawden EG, et al. The landscape of CD28, CD80, CD86, CTLA4, and ICOS DNA methylation in head and neck squamous cell carcinomas. Epigenetics. 2020;15(11):1195-212.

183. Zerdes I, Matikas A, Bergh J, Rassidakis GZ, Foukakis T. Genetic, transcriptional and post-translational regulation of the programmed death protein ligand 1 in cancer: biology and clinical correlations. Oncogene. 2018:37(34):4639-61.

184. Platanias LC. Mechanisms of type-l- and type-II-interferon-mediated signalling. Nat Rev Immunol. 2005;5(5):375-86.

185. Lee SJ, Jang BC, Lee SW, et al. Interferon regulatory factor-1 is prerequisite to the constitutive expression and IFN-gamma-induced upregulation of B7H1 (CD274). FEBS Lett. 2006;580(3):755-62.

186. Liu Y, Huang Z, Wei Y, et al. Identification of STXBP6-IRF1 positive feedback loop in regulation of PD-L1 in cancer. Cancer Immunol Immunother. 2020; 70(2):275-287

187. Yan Y, Zheng L, Du Q, Yan B, Geller DA. Interferon regulatory factor 1 (IRF-1) and IRF-2 regulate PD-L1 expression in hepatocellular carcinoma (HCC) cells. Cancer Immunol Immunother. 2020;69(9):1891-903.

188. Shin DS, Zaretsky JM, Escuin-Ordinas H, et al. Primary Resistance to PD1 Blockade Mediated by JAK1/2 Mutations. Cancer Discov. 2017;7(2): 188-201.

189. Curiel TJ, Wei S, Dong $H$, et al. Blockade of B7-H1 improves myeloid dendritic cell-mediated antitumor immunity. Nat Med. 2003;9(5):562-7.

190. Xiong HY, Ma TT, Wu BT, Lin Y, Tu ZG. IL-12 regulates B7-H1 expression in ovarian cancer-associated macrophages by effects on NF-kappaB signalling. Asian Pac J Cancer Prev. 2014;15(14):5767-72.

191. Zhao Q, Xiao X, Wu Y, et al. Interleukin-17-educated monocytes suppress cytotoxic T-cell function through $\mathrm{B} 7-\mathrm{H} 1$ in hepatocellular carcinoma patients. Eur J Immunol. 2011;41(8):2314-22.

192. Karakhanova S, Meisel S, Ring S, Mahnke K, Enk AH. ERK/p38 MAP-kinases and $\mathrm{PI3K}$ are involved in the differential regulation of $\mathrm{B} 7-\mathrm{H} 1$ expression in DC subsets. Eur J Immunol. 2010;40(1):254-66.

193. Cheng Y, Li H, Deng Y, et al. Cancer-associated fibroblasts induce PDL1+ neutrophils through the IL6-STAT3 pathway that foster immune suppression in hepatocellular carcinoma. Cell Death Dis. 2018;9(4):422.

194. Tsukamoto H, Fujieda K, Miyashita A, et al. Combined Blockade of IL6 and PD-1/PD-L1 Signaling Abrogates Mutual Regulation of Their Immunosuppressive Effects in the Tumor Microenvironment. Cancer Res. 2018;78(17):5011-22

195. Baas M, Besancon A, Goncalves T, et al. TGFbeta-dependent expression of PD-1 and PD-L1 controls CD8(+) T cell anergy in transplant tolerance. Elife. 2016;5:e08133.

196. Ou JN, Wiedeman AE, Stevens AM. TNF-alpha and TGF-beta counterregulate PD-L1 expression on monocytes in systemic lupus erythematosus. Sci Rep. 2012;2:295.

197. Starke A, Wuthrich RP, Waeckerle-Men Y. TGF-beta treatment modulates PDL1 and CD40 expression in proximal renal tubular epithelial cells and enhances CD8 cytotoxic T-cell responses. Nephron Exp Nephrol. 2007; 107(1):e22-9. 
198. Ciardiello F, Tortora G. EGFR antagonists in cancer treatment. N Engl J Med. 2008;358(11):1160-74.

199. Li X, Lian Z, Wang S, Xing L, Yu J. Interactions between EGFR and PD-1/PDL1 pathway: Implications for treatment of NSCLC. Cancer Lett. 2018;418:1-9.

200. Wagner EF, Nebreda AR. Signal integration by JNK and p38 MAPK pathways in cancer development. Nat Rev Cancer. 2009:9(8):537-49.

201. Haddadi N, Lin Y, Travis G, Simpson AM, Nassif NT, McGowan EM. PTEN/ PTENP1: 'Regulating the regulator of RTK-dependent PI3K/Akt signalling', new targets for cancer therapy. Mol Cancer. 2018;17(1):37.

202. Owen KL, Brockwell NK, Parker BS. JAK-STAT signaling: a double-edged sword of immune regulation and cancer progression. Cancers (Basel). 2019; 11(12).

203. Song TL, Nairismagi ML, Laurensia Y, et al. Oncogenic activation of the STAT3 pathway drives PD-L1 expression in natural killer/T-cell lymphoma. Blood. 2018;132(11):1146-58.

204. Hoesel B, Schmid JA. The complexity of NF-kappaB signaling in inflammation and cancer. Mol Cancer. 2013;12:86.

205. Bi XW, Wang H, Zhang WW, et al. PD-L1 is upregulated by EBV-driven LMP1 through NF-kappaB pathway and correlates with poor prognosis in natural killer/T-cell lymphoma. J Hematol Oncol. 2016;9(1):109.

206. Wang W, Chapman NM, Zhang B, et al. Upregulation of PD-L1 via HMGB1Activated IRF3 and NF-kappaB Contributes to UV Radiation-Induced Immune Suppression. Cancer Res. 2019;79(11):2909-22.

207. Jin X, Ding D, Yan Y, et al. Phosphorylated RB Promotes Cancer Immunity by Inhibiting NF-kappaB Activation and PD-L1 Expression. Mol Cell. 2019; 73(1):22-35 e26

208. Antonangeli F, Natalini A, Garassino MC, Sica A, Santoni A, Di Rosa F. Regulation of PD-L1 Expression by NF-kappaB in Cancer. Front Immunol. 2020;11:584626.

209. Rajabi H, Alam M, Takahashi H, et al. MUC1-C oncoprotein activates the ZEB1/miR-200c regulatory loop and epithelial-mesenchymal transition. Oncogene. 2014;33(13):1680-9.

210. Jing $X$, Yang F, Shao C, et al. Role of hypoxia in cancer therapy by regulating the tumor microenvironment. Mol Cancer. 2019;18(1):157.

211. Dang CV. MYC on the path to cancer. Cell. 2012;149(1):22-35.

212. Han H, Jain AD, Truica Ml, et al. Small-Molecule MYC Inhibitors Suppress Tumor Growth and Enhance Immunotherapy. Cancer Cell. 2019;36(5):48397 e415.

213. Donati B, Lorenzini E, Ciarrocchi A. BRD4 and Cancer: going beyond transcriptional regulation. Mol Cancer. 2018;17(1):164.

214. Shaw AT, Engelman JA. ALK in lung cancer: past, present, and future. J Clin Oncol. 2013;31(8):1105-11.

215. Comoglio PM, Trusolino L, Boccaccio C. Known and novel roles of the MET oncogene in cancer: a coherent approach to targeted therapy. Nat Rev Cancer. 2018;18(6):341-58.

216. Shaulian E, Karin M. AP-1 as a regulator of cell life and death. Nat Cell Biol. 2002;4(5):E131-6.

217. Chakrabarti J, Holokai L, Syu L, et al. Hedgehog signaling induces PD-L1 expression and tumor cell proliferation in gastric cancer. Oncotarget. 2018; 9(100):37439-57.

218. Lipson EJ, Lilo MT, Ogurtsova A, et al. Basal cell carcinoma: PD-L1/PD-1 checkpoint expression and tumor regression after PD-1 blockade. J Immunother Cancer. 2017;5:23.

219. Duffy MJ, Synnott NC, Crown J. Mutant p53 as a target for cancer treatment. Eur J Cancer. 2017:83:258-65.

220. Hayes J, Peruzzi PP, Lawler S. MicroRNAs in cancer: biomarkers, functions and therapy. Trends Mol Med. 2014;20(8):460-9.

221. Gong AY, Zhou R, Hu G, et al. MicroRNA-513 regulates B7-H1 translation and is involved in IFN-gamma-induced B7-H1 expression in cholangiocytes. J Immunol. 2009;182(3):1325-33.

222. Yee D, Shah KM, Coles MC, Sharp TV, Lagos D. MicroRNA-155 induction via TNF-alpha and IFN-gamma suppresses expression of programmed death ligand-1 (PD-L1) in human primary cells. J Biol Chem. 2017; 292(50):20683-93.

223. Sonkoly E, Janson P, Majuri ML, et al. MiR-155 is overexpressed in patients with atopic dermatitis and modulates T-cell proliferative responses by targeting cytotoxic T lymphocyte-associated antigen 4. J Allergy Clin Immunol. 2010;126(3):581-9 e581-520.

224. de Jong VM, Zaldumbide A, van der Slik AR, Persengiev SP, Roep BO, Koeleman BP. Post-transcriptional control of candidate risk genes for type 1 diabetes by rare genetic variants. Genes Immun. 2013;14(1):58-61 .
225. Kataoka K, Shiraishi Y, Takeda Y, et al. Aberrant PD-L1 expression through 3'UTR disruption in multiple cancers. Nature. 2016;534(7607):402-6.

226. Gibson HM, Hedgcock CJ, Aufiero BM, et al. Induction of the CTLA-4 gene in human lymphocytes is dependent on NFAT binding the proximal promoter. J Immunol. 2007;179(6):3831-40.

227. Wu Y, Borde M, Heissmeyer $V$, et al. FOXP3 controls regulatory $T$ cell function through cooperation with NFAT. Cell. 2006;126(2):375-87.

228. Oyewole-Said D, Konduri V, Vazquez-Perez J, Weldon SA, Levitt JM, Decker WK. Beyond T-Cells: Functional Characterization of CTLA-4 Expression in Immune and Non-Immune Cell Types. Front Immunol. 2020;11:608024.

229. Nagaraju K, Raben N, Villalba ML, et al. Costimulatory markers in muscle of patients with idiopathic inflammatory myopathies and in cultured muscle cells. Clin Immunol. 1999;92(2):161-9.

230. Alegre ML, Noel PJ, Eisfelder BJ, et al. Regulation of surface and intracellular expression of CTLA4 on mouse T cells. J Immunol. 1996;157(11):4762-70.

231. Srahna M, Van Grunsven LA, Remacle JE, Vandenberghe P. CTLA-4 interacts with STAT5 and inhibits STAT5-mediated transcription. Immunology. 2006; 117(3):396-401.

232. Mittal AK, Chaturvedi NK, Rohlfsen RA, et al. Role of CTLA4 in the proliferation and survival of chronic lymphocytic leukemia. PLoS One. 2013; 8(8):e70352.

233. Kong KF, Fu G, Zhang Y, et al. Protein kinase C-eta controls CTLA-4mediated regulatory T cell function. Nat Immunol. 2014;15(5):465-72.

234. Huang Z, Yao F, Liu J, et al. Up-regulation of circRNA-0003528 promotes mycobacterium tuberculosis associated macrophage polarization via downregulating miR-224-5p, miR-324-5p and miR-488-5p and up-regulating CTLA4. Aging (Albany NY). 2020;12(24):25658-72.

235. Schneider H, Martin M, Agarraberes FA, et al. Cytolytic T lymphocyteassociated antigen-4 and the TCR zeta/CD3 complex, but not CD28, interact with clathrin adaptor complexes AP-1 and AP-2. J Immunol. 1999;163(4): 1868-79.

236. Shiratori T, Miyatake S, Ohno H, et al. Tyrosine phosphorylation controls internalization of CTLA-4 by regulating its interaction with clathrinassociated adaptor complex AP-2. Immunity. 1997;6(5):583-9.

237. Linsley PS, Bradshaw J, Greene J, Peach R, Bennett KL, Mittler RS. Intracellular trafficking of CTLA-4 and focal localization towards sites of TCR engagement. Immunity. 1996;4(6):535-43.

238. Valk E, Leung $R$, Kang H, Kaneko K, Rudd CE, Schneider $H$. T cell receptorinteracting molecule acts as a chaperone to modulate surface expression of the CTLA-4 coreceptor. Immunity. 2006;25(5):807-21.

239. Banton MC, Inder KL, Valk E, Rudd CE, Schneider H. Rab8 binding to immune cell-specific adaptor LAX facilitates formation of trans-Golgi network-proximal CTLA-4 vesicles for surface expression. Mol Cell Biol. 2014; 34(8):1486-99.

240. Mead Kl, Zheng Y, Manzotti CN, et al. Exocytosis of CTLA-4 is dependent on phospholipase D and ADP ribosylation factor-1 and stimulated during activation of regulatory T cells. J Immunol. 2005;174(8):4803-11.

241. Lo B, Zhang K, Lu W, et al. AUTOIMMUNE DISEASE. Patients with LRBA deficiency show CTLA4 loss and immune dysregulation responsive to abatacept therapy. Science. 2015;349(6246):436-40.

242. Fu W, Ergun A, Lu T, et al. A multiply redundant genetic switch 'locks in' the transcriptional signature of regulatory T cells. Nat Immunol. 2012;13(10):972-80.

243. Zhang JJ, Zhang QS, Li ZQ, Zhou JW, Du J. Metformin attenuates PD-L1 expression through activating Hippo signaling pathway in colorectal cancer cells. Am J Transl Res. 2019;11(11):6965-76.

244. Cai S, Chen Z, Wang Y, et al. Reducing PD-L1 expression with a selfassembled nanodrug: an alternative to PD-L1 antibody for enhanced chemo-immunotherapy. Theranostics. 2021;11(4):1970-81.

245. Jiao S, Xia W, Yamaguchi H, et al. PARP Inhibitor Upregulates PD-L1 Expression and Enhances Cancer-Associated Immunosuppression. Clin Cancer Res. 2017:23(14):3711-20.

246. Wang $S$, Yao F, Lu X, et al. Temozolomide promotes immune escape of GBM cells via upregulating PD-L1. Am J Cancer Res. 2019;9(6):1161-71.

247. Booth L, Roberts JL, Poklepovic A, Dent P. [pemetrexed + sildenafil], via autophagy-dependent HDAC downregulation, enhances the immunotherapy response of NSCLC cells. Cancer Biol Ther. 2017;18(9): 705-14.

248. Zhou B, Guo L, Zhang B, et al. Disulfiram combined with copper induces immunosuppression via PD-L1 stabilization in hepatocellular carcinoma. Am J Cancer Res. 2019;9(11):2442-55. 
249. Jabbarzadeh Kaboli P, Salimian F, Aghapour S, et al. Akt-targeted therapy as a promising strategy to overcome drug resistance in breast cancer - A comprehensive review from chemotherapy to immunotherapy. Pharmacol Res. 2020;156:104806.

250. Iwata TN, Ishii C, Ishida S, Ogitani Y, Wada T, Agatsuma T. A HER2Targeting Antibody-Drug Conjugate, Trastuzumab Deruxtecan (DS8201a), Enhances Antitumor Immunity in a Mouse Model. Mol Cancer Ther. 2018;17(7):1494-503.

251. Liang J, Wang L, Wang C, et al. Verteporfin Inhibits PD-L1 through Autophagy and the STAT1-IRF1-TRIM28 Signaling Axis. Exerting Antitumor Efficacy. Cancer Immunol Res. 2020;8(7):952-65.

252. Llopiz D, Ruiz M, Villanueva L, et al. Enhanced anti-tumor efficacy of checkpoint inhibitors in combination with the histone deacetylase inhibitor Belinostat in a murine hepatocellular carcinoma model. Cancer Immunol Immunother. 2019;68(3):379-93.

253. Yi M, Jiao D, Xu H, et al. Biomarkers for predicting efficacy of PD-1/PD-L1 inhibitors. Mol Cancer. 2018;17(1):129.

254. Akinleye A, Rasool Z. Immune checkpoint inhibitors of PD-L1 as cancer therapeutics. J Hematol Oncol. 2019;12(1):92.

255. Buchbinder El, Desai A. CTLA-4 and PD-1 Pathways: Similarities, Differences, and Implications of Their Inhibition. Am J Clin Oncol. 2016;39(1):98-106.

256. Duffy AG, Ulahannan SV, Makorova-Rusher O, et al. Tremelimumab in combination with ablation in patients with advanced hepatocellular carcinoma. J Hepatol. 2017;66(3):545-51.

257. Podlesnykh SV, Abramova KE, Gordeeva A, Khlebnikov Al, Chapoval Al. Peptide blocking CTLA-4 and B7-1 interaction. Molecules. 2021;26(2).

258. Zhang $X$, Han S, Kang Y, et al. SAHA, an HDAC inhibitor, synergizes with tacrolimus to prevent murine cardiac allograft rejection. Cell Mol Immunol. 2012;9(5):390-8.

259. Oh BR, Suh DH, Bae D, et al. Therapeutic effect of a novel histone deacetylase 6 inhibitor, CKD-L, on collagen-induced arthritis in vivo and regulatory T cells in rheumatoid arthritis in vitro. Arthritis Res Ther. 2017; 19(1):154.

260. Mimura K, Kua LF, Shiraishi K, et al. Inhibition of mitogen-activated protein kinase pathway can induce upregulation of human leukocyte antigen class I without PD-L1-upregulation in contrast to interferon-gamma treatment. Cancer Sci. 2014;105(10):1236-44.

\section{Publisher's Note}

Springer Nature remains neutral with regard to jurisdictional claims in published maps and institutional affiliations.

Ready to submit your research? Choose BMC and benefit from:

- fast, convenient online submission

- thorough peer review by experienced researchers in your field

- rapid publication on acceptance

- support for research data, including large and complex data types

- gold Open Access which fosters wider collaboration and increased citations

- maximum visibility for your research: over $100 \mathrm{M}$ website views per year

At $\mathrm{BMC}$, research is always in progress.

Learn more biomedcentral.com/submissions 